Verena Dolle

\title{
Ein «Brasilianer» in Paris: Vicente Huidobro
}

angekommen

aufgebrochen

gastling $^{1}$

\section{Einleitung: Migration und Avantgarde - ein inspirierendes Treffen?}

Den Neologismus «Gastling» des spanisch-deutschen Dichters J.F.A. Oliver zum Ausgangspunkt meiner Überlegungen nehmend, mit dem dieser im Gedichtband gleichen Titels (1993) die zwiespältigen Erfahrungen eines Migranten in einem fremden Land zum Ausdruck gebracht hat, widmet sich dieser Beitrag der Frage, wie Migrationserfahrung und kulturelle Innovation im Werk von Vicente Huidobro (1893-1948), einem der herausragenden chilenischen Dichter des 20. Jahrhunderts, ineinanderwirken. Huidobro ist über Jahre hinweg Teil der internationalen polyglotten Avantgardebewegungen in Paris gewesen, wo er von Ende 1916 bis 1925 und von 1927 bis 1932 lebte. Er gilt vielen als Begründer der lateinamerikanischen (literarischen) Avantgarden, der avantgardistische Ideen von Paris aus nach Lateinamerika transportierte und den chilenischen lyrischen Diskurs um das Thema der Mobilität, des technischen Fortschritts und der Modernisierung bereicherte. ${ }^{2}$

Zugleich gilt Huidobro, der bereits von Chile aus vor 1916 durch die Herausgabe seiner Zeitschriften in Kontakt mit europäischen Schriftstellern und den dortigen avantgardistischen Überlegungen, wie etwa dem Futurismus, stand,

1 José F.A Oliver: Gastling. Berlin: Das Arabische Buch 1993, S. 9.

2 So etwa Jorge Schwartz: Chile. In: Ders.: Las vanguardias latinoamericanas. Textos programáticos y críticos. Madrid: Cátedra 1991, S. 65-68, Alfredo Bosi: La parábola de la (sic) vanguardias latinoamericanas. In: Jorge Schwartz (Hg.): Las vanguardias latinoamericanas. Textos programáticos y críticos. Madrid: Cátedra 1991, S. 62, Nelson Osorio Tejeda: Prólogo. In: Ders. (Hg.): Manifiestos, proclamas y polémicas de la vanguardia literaria hispanoamericana. Caracas: Biblioteca Ayacucho 1988, S. XX und Octavio Paz: Los hijos del limo. Del romanticismo a la vanguardia. Barcelona: Seix Barral ${ }^{3} 1990$ (Biblioteca de Bolsillo); zu Huidobro und Chile, vgl. Ana Pizarro: Huidobro: noticias del futuro. In: Patricio Lizama/María Inés Zaldívar: Las vanguardias literarias en Chile. Bibliografia y antología crítica. Madrid/Frankfurt a.M.: Iberoamericana/Vervuert 2009, S. 447.

Ә Open Access. (c) 2020 Verena Dolle, publiziert von De Gruyter. (c) BY-NC-ND Dieses Werk ist lizenziert unter der Creative Commons Attribution-NonCommercial-NoDerivatives 4.0 Lizenz. https://doi.org/10.1515/9783110679366-015 
unbestritten als Katalysator für die spanischen Avantgardebewegungen. ${ }^{3}$ Dies wird deutlich an Äußerungen der Madrider Akteure Rafael Cansinos-Assens und Guillermo de Torre, die auf Huidobro als denjenigen verweisen, der ihnen im Sommer 1918 von Paris aus die neuen Dichter und Strömungen, darunter den von ihm selbst vertretenen creacionismo, nahebrachte. ${ }^{4}$

Huidobro bekannte sich nicht nur enthusiastisch zu Paris, das zum Kristallisationspunkt einer kosmopolitischen und polyglotten, international mobilen Avantgarde wird, die ihre Ideen in andere Räume innerhalb und außerhalb Europas trug und Wien, der Hauptstadt des 1918 zusammengebrochenen Habsburgerreiches, den Rang als kulturelles Zentrum zunehmend ablief. ${ }^{5}$ Auch sein Werk ist von dem Aufenthalt entscheidend geprägt: Zum einen verfolgte er über Jahre hinaus eine zweisprachige Publikationsstrategie und publizierte seine Gedichtbände zwischen 1917 und 1925 zuerst auf Französisch, dann auf Spanisch, um sowohl ein franko- als auch ein hispanophones Publikum zu erreichen, zum anderen ist er der einzige der in Paris tätigen, oft nicht aus Frankreich stammenden (literarischen) Avantgardisten, der eine spezifische Übersetzungstheorie, nämlich von der uneingeschränkten Übertragbarkeit von einer in eine andere Sprache postuliert. ${ }^{6}$ Die Forschung hat sich bisher vor allem Huidobros avantgardistischen Ideen, dem creacionismo, seinen Erneuerungen der spanischsprachigen Lyrik und seiner Übersetzungstheorie gewidmet, den Blick dabei aber eher

3 Vgl. Esther Sánchez-Pardo: Vicente Huidobro and William Carlos Williams. Hemispheric Connections or How to Create Things with Words. In: International Yearbook of Futurism Studies 7 (2017), S. 185; Victoriano Alcantud: Creacionismo y cubismo literario: Vicente Huidobro, «el que trajo las gallinas». In: Victoriano Alcantud (Hg.): Hacedores de imágenes. Propuestas estéticas de las primeras vanguardias en España (1918-1925). Granada: Ed. Comares, S. $106 f$.

4 So Cansinos in der Zeitschrift Cosmópolis von 1918: «el creacionismo [...] cuya paternidad compartió (Huidobro) allá en París con otro singular poeta Pedro Reverdy [...] y cuyo evangelio práctico recogió en un libro, Horizon carré» (Victoriano Alcantud: Hacedores de imágenes, S. 133). Morales hebt die Katalysatorfunktion des Chilenen hervor: «la irrupción de un elemento exterior para que el mecanismo se ponga en marcha»; (André Morales: Huidobro en España. In: Vicente Huidobro: Obra poética. Herausgegeben von Cedomil Goic. Madrid u. a.: Colección Archivos 2003, S. 14091422, hier 1411). Madrid bot Huidobro als Reisendem zwischen der europäischen Metropole Paris und Chile - quasi auf der Durchreise über Madrid und Cádiz - eine Plattform, die er in Paris aus verschiedenen Gründen (sprachliche Hürde des Französischen, Konkurrenz anderer Dichter) nicht für sich allein hatte. Vgl. zur Beziehung zwischen den spanischen Avantgardisten und Huidobro zwischen 1918 und 1925, Victoriano Alcantud: Hacedores de imágenes, v. a. S. 106-133.

5 Vgl. Waldo Rojas: Huidobro a la hora de las vanguardias: acercamiento a su obra poética en francés. In: Patricio Lizama/María Inés Zaldívar (Hg.): Las vanguardias literarias en Chile. Bibliografía y antología crítica. Madrid/Frankfurt a. M.: Iberoamericana/Vervuert 2009, S. 485.

6 Vgl. Daniel Balderston: Huidobro and the Notion of Translatability. In: Fragmentos: Revista de Lingua e Literatura Estrangeiras da Universidade Federal de Santa Catarina 3, 1 (1990), S. 61. 
weniger auf die Rolle gerichtet, die der Status als Migrant in seinem Schaffen spielt. ${ }^{7}$ Im Folgenden soll diesem Aspekt, ausgehend von Flussers Überlegungen zu Migration als Voraussetzung für Freiheit und Kreativität, nachgegangen und Huidobros - oftmals polemische - Stellungnahmen der Pariser Jahre neu beleuchtet werden.

\section{I.a Avantgarde}

Huidobro begibt sich auf der Flucht vor dem chilenischen Provinzialismus Ende 1916 in den hot spot des avantgardistischen Kunstschaffens, Paris. ${ }^{8}$ Hier sind seit den 1900er Jahren vor allem Künstler unterschiedlicher Nationalitäten aktiv, die tradierte, akademische Formen des Kunstschaffens in allen Bereichen - Bildhauerei, Malerei, Literatur, Musik - in Frage stellen, die über disziplinäre Grenzen der Künste miteinander vernetzt sind und in Austausch stehen und neue erproben. ${ }^{9}$ Auch wenn es sich als schwierig herausstellt, den Begriff der Avantgarde allgemeingültig $\mathrm{zu}$ definieren, so lässt sich doch ein gewisser gemeinsamer Nenner bestimmen: künstlerische Verfahren, die je nach Umfeld und in Abhängigkeit von der historischen Situation (künstlerisch und politisch) innovativ sind, sich gegenüber Bestehendem oftmals radikal programmatisch als Ruptur abgrenzen, und von als «erstarrt» verstandenen Ausdrucksformen und -weisen Abstand nehmen. Für die historischen Avantgarden des ersten Drittels des 20. Jahrhunderts, in denen der Chilene sich bewegte, ist auch die Frage maßgeblich, wie technischer Fortschritt, Modernisierung und Industrialisierung angemessen künstlerisch/literarisch verarbeitet werden können. ${ }^{10}$ Innovatives Potential kann aber auch in der (Wieder-)Anknüpfung an (vergessene oder gering geschätzte) literarische Traditionen liegen, wie etwa bei der spanischen generación de 1927, die die über Jahrhunderte «verpönten» spanischen Barockdichter wie etwa Góngora wieder aufwertete.

7 Forschungsstand s. Fußnote 21.

8 Explizit hat Huidobro mit seiner Ankunft in Paris weniger den Anschluss an die spanischen als vielmehr an die nicht-spanischen Kreise gesucht (vgl. Octavio Paz: Los hijos del limo, S. 202; René de Costa: Careers of the Poet. Oxford: University Press 1984, S. 59).

9 Es sind auch Künstlerinnen in den Avantgardebewegungen tätig gewesen, deren Schaffen aber durch die zeitbedingt größere Sichtbarkeit der Männer und den wissenschaftlichen Fokus (von Männern) auf sie in den Hintergrund trat. Erst in jüngerer Zeit werden sie stärker in den Blick genommen, vgl. etwa für den deutschen Raum: Ingrid Pfeiffer/Max Hollein (für die Schirn Kunsthalle Frankfurt) (Hg.): STURM-FRAUEN. Künstlerinnen der Avantgarde in Berlin 1910-1932. Köln: Wienand Verlag 2015.

10 Vgl. Ana Pizarro: Huidobro: noticias del futuro, S. 447. 
Für die oben genannten historischen Avantgarden sei hier der Definition des mexikanischen Schriftstellers Padilla gefolgt:

\begin{abstract}
Las vanguardias fueron el último destello, la consumación del Romanticismo, pero fueron también el anticipo de la hiperpenetración del capitalismo en todos los dominios de la vida actual, incluido el del arte. En las vanguardias está el deseo de negarlo todo y experimentarlo todo, pero también la hábil gestión del capital semiótico, la inserción en el mercado del arte, la negociación con la cultura de masas. ${ }^{11}$
\end{abstract}

Basierend auf Octavio Paz (1990) sieht Padilla sie als letzte Ausprägung der Romantik, mit ihrer Absolutsetzung der Kunst, ihrem Negierungscharakter, verweist aber gleichwohl auf die Vorwegnahme («anticipo») des Kapitalismus und seinen Einfluss auf alle Bereiche sowie auf ein merkantiles Bewusstsein der Künstler, die ganz gezielt bestimmte (Massen-)Märkte und globale Zielgruppen in den Blick nehmen würden. ${ }^{12}$ Eymar stellt den «afán cosmopolita» der avantgardistischen Ästhetik heraus. ${ }^{13}$

Waldo Rojas verweist in seiner Charakterisierung der historischen Pariser Avantgarden zwar ebenfalls auf die Suche nach neuen ästhetischen Verfahren und die Abgrenzung vom Bestehenden als gemeinsamen Nenner, doch geht er stärker noch auf den Druck der Vermarktung der Ideen als etwas Neues und vor allem auf soziale Praktiken wie den Konkurrenzkampf innerhalb von und zwischen Gruppen um (mediale) Aufmerksamkeit ein, der sich in z.T. erbittert ausgefochtenen Ansprüchen auf die Originalität der eigenen Ideen und ebenso erbittert formulierten Vorwürfen des Plagiats manifestierte, die die beteiligten Künstler dazu zwang, Position für oder wider etwas oder jemanden zu beziehen. ${ }^{14}$

11 José Ignacio Padilla: Vicente Huidobro: Entrar y salir del lenguaje. In: Ders.: El terreno en disputa es el lenguaje: ensayos sobre la poesía latinoamericana. Madrid/Frankfurt a. M.: Iberoamericana/Vervuert 2014, S. 199.

12 Konkret verweist Padilla darauf, dass Huidobro global - d. h. in der westlichen Hemisphäre sehr aktiv war, und nicht nur Frankreich, Spanien und sein Heimatland Chile, sondern auch die USA (sowohl New York als auch Hollywood) und England bereiste (José Ignacio Padilla: El terreno en disputa es el lenguaje, S. 202) und damit die Verwaltung des eigenen «semiotischen Kapitals» in die Hand nahm.

13 Marcos Eymar Benedicto: La poética de la autotraducción en tres escritores bilingües francohispánicos: Vicente Huidobro, Juan Larrea y Ventura García Calderón. In: Pierre Civil/Françoise Crémoux (Hg.): Actas del XVI Congreso de la Asociación Internacional de Hispanistas: Nuevos caminos del hispanismo. París, del 9 al 13 de julio de 2007. Madrid/Frankfurt: Iberoamericana/ Vervuert 2010, S. 130.

14 "[...] una multitud de movimientos espirituales, escuelas literarias y artísticas cuya novedad radical o pretendidamente tal se acogía a la etiqueta colectiva de un apelativo aparejado del sufjo ismo y a menudo desconcertante. Bajo esa bandera son innumerables los grupos en buena parte muy juveniles que surgen día a día -y día a día se extinguen- dando cuenta en efímeras revistas o 
Für Huidobro ist festzuhalten, dass er sich bereits als Avantgardist versteht, bevor er nach Paris kam, denn sein poetisches Manifest «Non serviam», in dem er die Abkehr von einer mimetischen Kunst postuliert, trug er 1916 in Buenos Aires vor. In Paris bringt er sich sofort in avantgardistische Kreise ein: durch Mitarbeit an bzw. Gründung und Mit-Finanzierung von - meist - kurzlebigen Zeitschriften wie Nord-Sud (14 Ausgaben von März 1917 bis Oktober 1918). Er verschreibt sich dem von der Malerei von Juan Gris und Pablo Picasso inspirierten literarischen Kubismus und Simultaneismus, der von Guillaume Apollinaire und Pierre Reverdy aufgenommen wurde, ${ }^{15}$ dem Ausprobieren der Grenzüberschreitung hin zur visuellen Dichtung, er produziert «poemas pintados» und sieht sich als Begründer des creacionismo, eines nicht referentiell und anekdotisch arbeitenden lyrischen Schaffensprozesses, der den modernismo Daríoscher Prägung hinter sich lassen will, eine kosmopolitische Poetik des Primats des Bildes vor der sprachlichen Transferierbarkeit von Lyrik postuliert, und eine Entgrenzung der Literatur hin zu anderen universalen Künsten wie Musik, Malerei und Bildhauerei einfordert. Er verfolgt zusammen mit der ukrainischstämmigen Künstlerin Sonia Delaunay ein für die damalige Zeit innovatives Projekt der Verbindung von Mode und Literatur und wendet sich schließlich dem neuen Medium der Zeit, dem (Stumm-)Film zu: Er verfasst Drehbücher, setzt sich mit filmischer Schreibweise auseinander und schreibt einen Roman über einen genuin spanischen Heroen, den Cid, den er in die Zukunft transferiert. In seinem Langgedicht Altazor (1931) verarbeitet er sprachliches, nicht mehr semantisierbares Klangmaterial (v.a. im letzten Gesang) und beschreitet damit für die spanischsprachige Literatur der Zeit absolutes Neuland. Daneben verfasst er im Stil der Zeit programmatische Manifeste, die bei ihm oft sehr autobiographisch geraten und einen gewissen Verteidigungsgestus enthalten (s.u.).

panfletos del nacimiento de nuevas tendencias y doctrinas estéticas, enarbolando manifiestos y proclamas, acompañadas de polémicas encarnizadas de precedencia temporal y reclamo de pergaminos de anterioridad, de litigios de plagio o sencillamente querellas inherentes a la estrategia del exclusivismo a ultranza de cada grupo, dando cuenta en suma de una voluntad imperiosa de ruptura con el estado de cosas vigente y de su hostilidad exasperada hacia la tradición» (Waldo Rojas: Huidobro a la hora de las vanguardias: acercamiento a su obra poética en francés, S. 481).

15 Vgl. Octavio Paz: Los hijos del limo, S. 176. 


\section{I.b Migration und Huidobros «privilegierte Mobilitäts}

In der Fokussierung auf die avantgardistischen Aktivitäten eines einzelnen kann schnell aus dem Blick geraten, dass künstlerisches Schaffen und Erfolg bzw. Sichtbarkeit auch von anderen Faktoren abhängen oder beeinflusst werden, konkret von der Migrationssituation der beteiligten KünstlerInnen und ihrem Verhältnis zur aufnehmenden Mehrheitsgesellschaft und ihrer (alten) Heimat. Deshalb ist es aufschlussreich, sich zu vergegenwärtigen, dass Huidobro trotz seiner (zuerst) auf Französisch publizierten Gedichtbände (zwischen 1917 und 1925) in französischen Literaturgeschichten zu den historischen Pariser Avantgarden nicht bzw. nur marginal erwähnt wird. ${ }^{16}$ Ebenso, dass es m.W. keine Interviews mit ihm in französischen Organen, sondern nur in spanischsprachigen gibt, wo er dann aber z.T. als in Chile geborener französischer Dichter (s.u.) tituliert und ihm ein starker Assimilationswille unterstellt wird. Schließlich, dass Huidobro von französischen Zeitgenossen in seiner Rolle in der Pariser Szene als «marginal» und unbedeutend, ja sogar als «Brasilianer» wahrgenommen wurde. ${ }^{17}$ Auch wenn dieser Jahrzehnte später erfolgten Attribuierung mit gewisser Skepsis $\mathrm{zu}$ begegnen ist, so lässt sich zumindest erahnen, mit welcher Ignoranz und Arroganz ein Zugereister/Migrant konfrontiert werden konnte und welche Maßnahmen er ergreifen musste, um beachtet zu werden, oder, mit Bourdieu bzw. Padilla gesprochen, um sein semiotisches Kapital gewinnbringend anlegen zu können.

Vicente Huidobro, der Ende 1916 mit Ehefrau und Kindern bis 1925 und dann von 1928 bis 1932 seinen Hauptwohnsitz in Paris nahm, kann wie viele andere KünstlerkollegInnen aus der Pariser Avantgardeszene, etwa Guillaume Apollinaire, Juan Gris, Jacques Lipchitz, Sonia Delaunay, der Elsässer Hans (Jean) Arp oder Tristan Tzara, als Migrant gelten, denn als «Wanderung» zählt jede dauerhafte oder vorübergehende Wohnsitzverlagerung (in ein anderes Land). ${ }^{18} \mathrm{Da}$ er während dieser Zeit zwischen seinen Wohnorten in Paris und Chile regelmäßig pendelte und damit seine «soziale Bindung an die Herkunftsgesellschaft beibehielt», die Beziehung zum Heimatland Chile weder medial noch persönlich abbricht, sondern seine Aufenthalte dort mit Interviews und Artikeln entsprechend

16 Vgl. Waldo Rojas: Huidobro a la hora de las vanguardias: acercamiento a su obra poética en francés, S. 472f.

17 So Gonzalo Rojas 1994, der sich seinerseits an ein Gespräch mit Benjamin Péret, Vertreter des Surrealismus, im Jahr 1953 erinnert (vgl. Waldo Rojas: Huidobro a la hora de las vanguardias: acercamiento a su obra poética en francés, S. 473, Nr. 3). Vgl. auch De Costa: Careers of a Poet.

18 Vgl. Petrus Han: Soziologie der Migration. Erklärungsmodelle, Fakten, Politische Konsequenzen, Perspektive. Stuttgart: Lucius \& Lucius Verlagsgesellschaft ${ }^{2} 2005$, S. 9. 
flankiert und da er sogar für das Amt des Präsidenten der Republik 1925 und für das Parlament jeweils erfolglos kandidierte, lässt er sich auch als Transmigrant bezeichnen. ${ }^{19}$

Bei Huidobros Wohnsitzverlagerung von Chile nach Paris im Jahre 1916 handelt es sich nicht um ein Verlassen müssen, sondern um «privilegierte Mobilität» im Sinne Lipphardts, ${ }^{20}$ also eine Mobilität, die ein spielerisches, flüchtiges Moment und die Möglichkeit, sich zu entziehen und jederzeit einen Ortswechsel vorzunehmen, inklusive Rückkehr, einschließt - anders als bei vielen anderen Künstlern, Literaten und Intellektuellen des 20. Jahrhunderts, die ihre Länder wegen politischer Schwierigkeiten, Verfolgung und Angst um Leib und Leben verlassen mussten und z.T. über Jahrzehnte nicht zurückkehren durften. Es ist also irreleitend, bei ihm von Exil oder Emigration zu sprechen und entsprechende theoretische Konzepte anzuwenden. Seine Mobilität war bis auf die durch knapper werdende finanzielle Mittel bedingte Rückkehr nach Chile 1932 freiwillig. ${ }^{21}$

19 Vgl. Ludger Pries: Internationale Migration. Bielefeld: Transcript ${ }^{4} 2013$, S. 9.

20 Vgl. Anna Lipphardt: Der Nomade als Theoriefigur, empirische Anrufung und LifestyleEmblem. Auf Spurensuche im Globalen Norden. In: Aus Politik und Zeitgeschichte 26/27 (2015). URL: http://www.bpb.de/apuz/208257/der-nomade-als-theoriefigur-empirische-anrufung-und-li festyle-emblem-auf-spurensuche-im-globalen-norden, S. 1-6, hier S. 4.

21 Es liegt auf der Hand, dass im Zuge der postkolonialen Studien mehrsprachige, mobile Dichter mit ihren mehrsprachigen Werken unter dem Aspekt des Nomadentums und der Hybridisierung analysiert werden, so auch Huidobro: Der kosmopolitische, nationale Grenzen überschreitende Anspruch des Werks sowie das Nomadische in der Biographie des Chilenen wird von Vastchenko (Alexis Vastchenko: Vicente Huidobro ou la création nomade. Une poésie à l'échelle du monde. In: Beïda Chikhi (Hg.): Destinées voyageuses. La patrie, la France, le monde. Paris: Presses de l'Université Paris-Sorbonne 2006) herausgestellt, der gleichzeitig eine auffällige Opposition zwischen sich als Teil eines französischen Kollektivs («Nous») und dem Anderen (dem Chilenen, der sich in einer fremden Sprache ausdrückt) aufmacht und damit Differenzen deutlich markiert. Die Mehrsprachigkeit des Werks in ihrer strategischen und poetologischen Dimension wird von Martínez/Ostrov (Carlos Démaso Martínez/Andrea Ostrov: Bilingüismo y vanguardia en Vicente Huidobro. In: Axel Gasquet (Hg.): Écrivains multilingues et écritures métisses: l'hospitalité des langues. Clermont-Ferrand: Presses Universitaires Blaise Pascal 2007), die Übersetzungspoetik und die auto-traducciones verschiedener Gedichte von Balderston (Daniel Balderston: Huidobro and the Notion of Translatability) und Eymar (Marcos Eymar Benedicto: La poética de la autotraducción en tres escritores bilingües franco-hispánicos: Vicente Huidobro, Juan Larrea y Ventura García Calderón; Marcos Eymar Benedicto: La langue plurielle. Le bilinguisme franco-espagnol dans la littérature hispano-américaine (1890-1950). Paris: Harmattan 2011) in den Blick genommen. Eine Deutung des berühmtesten Werkes Huidobros, des Langgedichts Altazor (1931), aus migrationstheoretischer Sicht wird von Alarcón-Arana (Esther M. Alarcón-Arana: Exilio e identidad: superación de las poéticas clásica y cristiana en Altazor de Vicente Huidobro. In: Scritture Migranti 8 (2014), S. 85f.) vorgelegt: ihr zufolge deute der Autor das traditionell negativ konnotierte Konzept von «Exil» mit Angst vor Entwurzelung (allegorisch) positiv um zur ersehnten poeti- 
Lebensgrundlage und Heimat waren nicht vernichtet, er konnte sich vielmehr aufgrund des Reichtums seiner Eltern lange Zeit ausschließlich seinen literarischen Aktivitäten und den damit verbundenen Reisetätigkeiten - in Europa, in Asien, zwischen den Kontinenten - widmen. Letztere - zwischen der Begründung und dem endgültigen Aufgeben des Pariser Wohnsitzes, also 1916-1932 - wurden derart häufig von ihm selbst in Interviews wie auch in Werken herausgestellt, dass er als «nomadische Existenz» (Lipphardt) bezeichnet werden kann, ${ }^{22}$ wie an diesem kurzen Überblick erkennbar wird:

Als Sohn aus einer reichen, konservativ katholischen Weinbauernfamilie in Chile, einer Mutter, die Zuhause einen literarischen Zirkel unterhält, unternimmt Huidobro im Laufe seines Lebens zahlreiche transatlantische Reisen, die erste im Alter von sieben Jahren zusammen mit der Familie. Nach Besuch des Jesuitenkollegs in Santiago, einem Literaturstudium an der Universidad de Chile und verschiedenen literarischen Aktivitäten, etwa der Herausgabe einer Zeitschrift, die ihn von Chile aus in Kontakt mit europäischen avantgardistischen Autoren brachte, schifft er sich 1916 von Buenos Aires, der kosmopolitischsten Stadt Lateinamerikas, mit Frau und Kindern nach Europa ein. ${ }^{23}$ Vom Zielhafen Cádiz aus reist er über Madrid nach Paris, wo er sich ab Dezember 1916 bis 1925 aufhält und literarisch

schen Freiheit und verbinde es mit seiner eigenen Identität als Dichter. Problematisch in ihrem Ansatz ist allerdings, dass der Exilbegriff für Huidobro nicht zutrifft, da es sich bei ihm um privilegierte Mobilität handelt und dass das die Allegorie konterkariende ironische Element von Altazor, auf das etwa Padilla als unauflösbare Verflechtung verweist (Ebda., S. 229f.) nicht berücksichtigt wird (s.u.). Esther Sánchez-Pardo: Vicente Huidobro and William Carlos Williams, S. 201, bezeichnet ihn als «émigré», was aufgrund seiner Biographie nicht zutreffend ist. Zur Wiederentdeckung Huidobros als Poet der Modernisierung im Chile der 1990er Jahre Pizarro (Ana Pizarro: Huidobro: noticias del futuro, v.a. ab S. 454). $\mathrm{Zu}$ den französischen Gedichtbänden Huidobros, zwischen 1917 und 1925, also während des ersten Paris-Aufenthalts publiziert, ist Rojas (Waldo Rojas: En torno a Automne régulier y Tout à coup: culminación y proyecciones de la andanza poética francesa de Vicente Huidobro. In: Vicente Huidobro: Obra poética. Herausgegeben von Cedomil Goic. Madrid u. a.: Colección Archivos 2003; Waldo Rojas: Huidobro a la hora de las vanguardias: acercamiento a su obra poética en francés) maßgeblich.

22 Lipphardt verweist auf die Konjunktur des Begriffs «Nomade» seit den 1980er Jahren, in denen sich der «Nomade [...] als zentrale Theoriefigur etabliert, die für ein hohes Maß an Mobilität sowie für Freiheit, Grenzüberschreitung und Nonkonformismus steht» (Anna Lipphardt: Der Nomade als Theoriefigur, empirische Anrufung und Lifestyle-Emblem, S. 1). Vgl. zur Vita von Huidobro den Überblick in Cedomil Goic: Cronología. In: Vicente Huidobro: Obra poética. Herausgegeben von Cedomil Goic. Madrid u. a. : Colección Archivos 2003, S. 1385-1403 sowie Volodia Teitelboim: Huidobro, la marcha infinita. Santiago de Chile: Ed. Sudamericana 1997.

23 Vgl. Ana Pizarro: Huidobro: noticias del futuro, S. 445-447. Pizarro (Ebda. S. 446) verweist auf die Abgeschottetheit Chiles inklusive der Hauptstadt Santiago und seiner konservativen Oligarchie zu Beginn des 20. Jahrhunderts im Gegensatz zu Argentinien und Buenos Aires, das durch die Lage am Atlantik und den Transatlantikhandel ganz anderen gesellschaftlichen Einflüssen und Dynamiken, resultierend aus der Einwanderung aus Europa, ausgesetzt ist. 
tätig ist. Er knüpft Kontakte mit zwei Generationen der künstlerischen, literarischen und musikalischen Avantgarde, die einen ca. 10 Jahre älter, die anderen gleich alt, mit der er zum Teil lange in Kontakt bleibt, zum Teil sich - schnell - zerstreitet: darunter die kubistischen Maler Pablo Picasso (aus Andalusien stammend) und Juan Gris (aus Katalonien), der Bildhauer jüdisch-litauischer Abstammung Jacques Lipchitz (seit 1909 in Paris), Francis Picabia und Joan Miró, Max Ernst, Paul Éluard und Blaise Cendrars, der Elsässer Hans (Jean) Arp. ${ }^{24}$ Einige von ihnen sind wie Huidobro auch aus künstlerischen Gründen nach Paris migriert. Unterbrochen wird dieser erste Pariser Aufenthalt durch eine Flucht vor den Wirren des Ersten Weltkrieges nach Beaulieu-près-Lorches bei Tours zusammen mit den Familien von Juan Gris und Jacques Lipchitz im Frühjahr 1918 (das einzige, was sich als erzwungene Mobilität bei ihm bezeichnen ließe), einen mehrmonatigen Aufenthalt in Madrid von Juli bis November 1918, einen kurzen Aufenthalt in Chile Ende 1918 bis Anfang 1919, um an der Hochzeit seiner Schwester teilzunehmen, sowie in der Folgezeit dann regelmäßige mehrwöchige bis mehrmonatige Aufenthalte in Madrid mit Publikations- und Vortragstätigkeiten, in denen er vielbeachtet Ideen der Pariser Avantgarde einbrachte und Kontakte zu der dortigen Intellektuellenszene aufnimmt, Rafael Cansinos Assens, Guillermo de Torre, Isaac del Vando-Villar, Mauricio Bacarisse und Ramón Gómez de la Serna sowie zu dem eigentlich in Paris wohnenden Künstlerehepaar Sonia und Robert Delaunay. ${ }^{25}$ Darüber hinaus hält er Vorträge in Berlin (1920) und Stockholm (1924) und steht in Briefkontakt mit dem Rumänen Tristan Tzara, Begründer des Dadaismus zusammen mit Hugo Ball und Hans Arp, in dessen in Zürich erscheinender Zeitschrift Dada (Nr. 3, 1918) er drei Gedichte aus seinem ersten auf Französisch erschienenen Band Horizon carré (1917) veröffentlicht, «Cow-boy», «Orage» und «Paysage», ebenso im Almanach Dada von Hülsenbeck $1920 .^{26}$

Er arbeitet bei avantgardistischen Zeitschriften mit. Wegen Fragen um die Finanzierung der Zeitschrift Nord-Sud und die Urheberschaft des creacionismo kommt es 1920 zum Streit und Bruch mit Pierre Reverdy ${ }^{27}$ und einer entsprechenden Gruppenbildung zwischen denen, die

24 Vgl. Goic, Cedomil: Cronología. In: Vicente Huidobro: Obra poética. Herausgegeben von Cedomil Goic. Madrid u.a.: Colección Archivos 2003, S. 1383-1406, hier S. 1389f.; Padilla, José Ignacio: Vicente Huidobro: Entrar y salir del lenguaje. In: Ders.: El terreno en disputa es el lenguaje: ensayos sobre la poesía latinoamericana. Madrid/Frankfurt a.M.: Iberoamericana/Vervuert 2014, S. 207-238, hier S. 207.

25 Das Ehepaar Delaunay wurde während seiner Ferien im Baskenland von der Kriegserklärung Frankreichs überrascht und bleibt während der Dauer des Krieges auf der Iberischen Halbinsel, in Madrid bzw. Portugal (vgl. Victoriano Alcantud: Hacedores de imágenes, S. 145), es handelt sich also um eine kriegsbedingte Zwangsmobilität. Zu Huidobros Madridaufenthalten vgl. André Morales: Huidobro en España, S. 1411-1418.

26 Eine positive Rezension zu «Cow-boy» in der New York Times macht deutlich, dass die Avantgarde über Europa hinaus rezipiert wurde, sie sich also einen internationalen Markt erschließt (vgl. Victoriano Alcantud: Hacedores de imágenes, S. 125), eine Rezeption, die durch manche suggestiven englischsprachigen Titel der ansonsten einsprachig Französisch oder Spanisch verfassten Gedichte sicherlich bestärkt wird (neben dem genannten Gedicht etwa auch «Globe-trotter» aus Automne régulier (1925), «Bay Rum» (für eine bestimmte Rumsorte) und «Hp» (für «Horsepower» als Modellbezeichnung für Automobile, herzlicher Dank an Stefan Böhm), erschienen in Poemas árticos (1918).

27 Vgl. Alcantud 2014, 1129. 
sich eindeutig gegen Huidobro positionieren, so u.a. Guillermo de Torre, Schwager von Jorge Luis Borges, und denen, die ihn verteidigen, so Gerardo Diego und Juan Larrea, seine spanischen «Schüler».

Im März 1925 kehrt er nach Chile zurück, nimmt dort am Junisalon teil, wo seine «poemas pintados» zusammen mit Werken von Lipchitz, Leger, Marcoussis und Picasso ausgestellt werden (vgl. Goic 2003a, 1394). Neben den künstlerischen Aktivitäten versucht er sich auf politischem Terrain und kandidiert - erfolglos - für das Präsidentenamt der Republik Chile und 1926 - ebenso erfolglos - für einen Sitz als Abgeordneter. Im August 1926 reist er wieder nach Paris, dann Mitte 1927 nach New York und Los Angeles, wo er Kontakte mit Filmschaffenden und dem Komponisten Edgar Varèse aufnimmt, der eins seiner Gedichte vertont, sowie für sein französischsprachiges Drehbuch zu Cagliostro einen Preis erhält, das er nach Scheitern der Verfilmung, tituliert als «novela-film», publiziert. Nach einem Aufenthalt in Chile reist er von dort mit einer neuen Partnerin nach Paris, wo er bis 1932 residiert, sich 1931 aber für mehrere Monate in Madrid aufhält und sowohl Altazor als auch Temblor de cielo zum Druck bringt (vgl. Morales 2003, 1418f.). Aufgrund finanzieller Schwierigkeiten durch die Welt-Wirtschaftskrise gibt er seinen Pariser Wohnsitz 1932 auf und kehrt nach Chile zurück.

Dort ist er weiterhin literarisch aktiv, mit Beiträgen in Zeitschriften bzw. ihrer Herausgabe, Vorträgen, Verbindung mit der chilenischen, vom Surrealismus inspirierten AvantgardeBewegung Mandrágora (aktiv seit 1932, offiziell gegründet 1938), die er ebenfalls beeinflusst hat, und führt erbitterte Polemiken mit Schriftstellerkollegen in Peru und Chile. ${ }^{28}$ Nach Ausbruch des Bürgerkriegs 1936 reist er nach Spanien, nimmt 1937 in Paris am Schriftstellerkongress der Association Internationale des Ecrivains pour la Défense de la Culture sowie am 2. Kongress der Intellektuellen in Valencia teil, kehrt dann aber nach Chile zurück. ${ }^{29}$ Ende 1944 reist er als Kriegsberichterstatter für eine chilenische und eine uruguayische Zeitung als Mitglied des Siebten US-amerikanischen Heeres, z.T. im Verbund mit der Division des französischen Generals Jean de Lattre de Tassigny nach Europa. Er zieht mit den französisch-amerikanischen Truppen in Berlin ein, scheint in Hitlers Quartier in Berchtesgaden gewesen zu sein und wird im April und Mai 1945 verwundet. Danach hält er sich in London und Paris auf und reist im August 1945 über New York, Rio de Janeiro und Buenos Aires zurück nach Chile, wo er 1948 im Alter von 55 Jahren an einer Hirnblutung stirbt. ${ }^{30}$

Nach dem zuvor Ausgeführten zum bewegten Leben Huidobros wird ersichtlich, dass er wie ein mobiler Künstler der 1980er Jahre avant la lettre anmutet, den Lipphardt wie folgt kennzeichnet:

28 Vgl. Belén Castro Morales: Ver y palpar: en el hipertexto de la escritura creacionista. In: Vicente Huidobro: Obra poética. Herausgegeben von Cedomil Goic. Madrid u.a.: Colección Archivos 2003, S. $1520 \mathrm{f}$.

29 Vgl. André Morales: Huidobro en España, S. 1419-1421.

30 Vgl. ebda., S. 1419-1421. Er unternimmt damit nicht nur die für reiche Lateinamerikaner übliche (touristische) Bildungsreise in das damals noch als Zentrum der Kultur angesehene Europa mit der mythischen Metropole Paris. 
Während die traditionelle Künstlerreise neue Perspektiven durch den Aufenthalt an unbekannten Orten eröffnet hatte, rückten nun zunehmend das Unterwegssein, der Transit und das Reisen selbst in den künstlerischen Fokus. Dabei griffen Künstlerinnen und Künstler aus unterschiedlichen Disziplinen zunehmend auf Strategien, Techniken und Präsentationsformen zurück, die Bewegung und Relokalisierung gezielt aufgreifen und fruchtbar machen. $\mathrm{Zu}$ einem Zeitpunkt, zu dem häufige, sich über weite Distanzen erstreckende Mobilität im Kunstbereich zu einem unverzichtbaren Karriere-Asset geworden ist, inszenieren sich heute zudem viele Künstlerinnen und Künstler im Rahmen ihrer öffentlichen Selbstdarstellung als Nomaden, das heißt als dauermobile kosmopolitische Grenzüberschreiter. ${ }^{31}$

Zwar verweist sie darauf, dass dies als Rückgriff auf die positive Darstellung des Nomaden bei Deleuze/Guattari ${ }^{32}$ als Theoriefigur zu verstehen sei, die in den hoch mobilen westlichen Gesellschaften des 21. Jahrhunderts jedoch «ihr subversives Potenzial verloren (habe) und zur gesamtgesellschaftlichen Norm geworden [sei]». ${ }^{33}$ Für Huidobro lässt sich dagegen konstatieren, dass seine unbezweifelbar hohe Mobilität noch nicht zur Norm geworden, sondern bereits zu Lebzeiten derart auffällig war, dass er unter den Zeitgenossen als «Handlungsreisender der Kunst» galt. ${ }^{34} \mathrm{Zu}$ fragen ist, inwieweit Huidobro sich in dieser Mobilität auch selbst inszeniert und sie für sein Werk fruchtbar macht, inwieweit diese Grenzüberschreitung ein subversives, etwa ein nationales Containerdenken aufbrechendes und Machtansprüche unterlaufendes Potenzial hat.

Vilem Flusser, jener Philosoph und Kultur- und Medienwissenschaftler, der in seiner Vita ein mehrfaches Exil erfahren hat, ${ }^{35}$ hat die Frage nach Kreativität in Verbindung mit Ver- bzw. Entwurzelung (Heimat bzw. Migration) besonders in den Blick genommen und plädiert dafür, jede Form von Migration (auch Vertreibung und Exil) als positive Situation der selbstbestimmten Freiheit zu nutzen. Flusser vertritt die Ansicht, dass in dem Augenblick, in dem Migranten ihre neue (u.U. erzwungene) «Freiheit» annehmen und sich nicht einer neuen, wieder fixierenden, verschiedene Zwänge ausübenden Heimat verschreiben, besonders

31 Anna Lipphardt: Der Nomade als Theoriefigur, empirische Anrufung und Lifestyle-Emblem, S. 3.

32 Er verkörpere die «Verbindung [...] dreier Aspekte: erstens Freiheit und Unabhängigkeit, zweitens Nonkonformismus und Avantgarde (oder zumindest Fortschritt) und drittens hochfrequentes Reisen über weite geografische Distanzen», Ebda., S. 3.

33 Ebda., S. 4.

34 Der chilenische Schriftsteller Ángel Cruchaga bezeichnet Huidobro bereits 1919 in einem Interview als «alma de viajero obsesionado por nuevas estrellas», Ángel Cruchaga: Conversando con Vicente Huidobro (1919). In: Cecilia García-Huidobro, Vicente Huidobro. A la intemperie. Entrevistas, S. 66.

35 Flusser floh 1940 vor den Nazis aus Prag über London nach Brasilien, das er nach 31 Jahren in der Zeit der Diktatur verließ und seinen Wohnsitz 1972 in Frankreich nahm. 
«kulturell innovativ» seien. In seinem Essay «Wohnung beziehen in der Heimatlosigkeit» heißt es:

Die Heimat ist zwar kein ewiger Wert, sondern eine Funktion..., aber wer sie verliert, der leidet. Er ist nämlich mit vielen Fasern an seine Heimat gebunden [...], jenseits seines wachen Bewußtseins. [...] Es sind zumeist geheime Fasern, die den Beheimateten an die Menschen und Dinge der Heimat fesseln. [...] Aber, nach dem Umschlagen der Vertriebenheit in Freiheitstaumel, der Frage «frei wovon?» in die Frage «frei wozu?», wird die geheimnisvolle Verwurzelung zu einer obskurantistischen Verstrickung, die es jetzt wie einen gordischen Knoten zu zerhauen gilt. Der Sich-selbst-Analysierende erkennt, dann, bis zu welchem Maß seine geheimnisvolle Verwurzelung in der Heimat seinen wachen Blick auf die Szene getrübt hat. Er erkennt nicht etwa nur, daß jede Heimat den in ihr Verstrickten auf ihre Art blendet und daß in diesem Sinn alle Heimaten gleichwertig sind, sondern vor allem auch, daß erst nach Überwindung dieser Verstrickung ein freies Urteilen, Entscheiden und Handeln zugänglich werden. ${ }^{36}$

Zur Freiheit des Migranten gehört, so Flusser, die Selbstbestimmung und eigene Entscheidung über Bindungen, die bei einem Nicht-Migrierten oft nicht hinterfragt werden: «[Freisein bedeutet] nicht das Zerschneiden der Bindungen an andere, sondern das Flechten dieser Verbindungen in Zusammenarbeit mit ihnen. $)^{37}$

Zwei Fragen sollen nach dieser biographie- und detaillastigen, im Kontext der Fragestellung unvermeidlichen Einführung nun ausgehend von Lipphardts und Flussers Überlegungen weiter verfolgt werden:

1. Welche Entwürfe von Zugehörigkeit oder Nicht-Zugehörigkeit und Freiheit lassen sich in den Äußerungen und Praktiken des Transmigranten Huidobro finden, welche in denen der französischen Mehrheitsgesellschaft, in der er für mehrere Jahre lebte und auf die er als Neuankömmling Bezug nehmen, sich positionieren muss? Hierzu werden faktuale Texte - Vorwörter, Interviews, Manifeste - untersucht, ebenso seine oft und heftig diskutierten Publikationsstrategien.

2. Wie lässt sich die laut Flusser kreative Situation des Migranten in seinem Werk in einer poetologischen Dimension wiederfinden - wie wird Reisen, Mobilität und Grenzüberschreitung und (Nicht-)Heimat thematisiert und inszeniert?

36 Vilém Flusser: Von der Freiheit des Migranten. Hamburg: CEP Europäische Verlagsanstalt 2013, S. $17 \mathrm{f}$.

37 Ebda., S. 20. 


\section{Von den Zugehörigkeiten des Migranten}

\section{II.a Identitätsmodellierungen}

Was die Frage der Zugehörigkeit zu einer bestimmten Gruppe (Künstler, Nation, Schicht, Ethnie) des hochmobilen Huidobro bzw. Freiheit von ihr angeht, so geben die Manifeste und Interviews Auskunft über seine Selbst-Verortung. In seinem Artikel «Littérature de la langue espagnole d'aujourd'hui» $(1920)^{38}$ hebt er das rückständig provinzielle «milieu hostile» in Chile bzw. spanischsprachigen Ländern insgesamt hervor, das ästhetischen Neuerungen feindlich gegenüberstehe und die Dichter, er selbst als Beispiel, dann heftig angreife. ${ }^{39}$ Demgegenüber lobt er Paris ${ }^{40}$, markiert durch die Ortsdeixis «ici» als Ort des Sprechers, und macht dessen Bedeutung als Zentrum künstlerischen Austauschs deutlich, in dem sich eine Gruppe von Künstlern gegenseitig positiv verstärke. Es wird deutlich, dass sich Huidobro im <Zentrum> Paris von seinem <peripheren> Heimatland massiv abgrenzt und mit einem sehr kritischen «wachen Blick» (Flusser) auf dieses schaut.

Noch expliziter findet sich eine spezifisch auf die Nation Chile bezogene ambigue Abgrenzung in dem in Paris gemachten, «Vincent Huidobro» betitelten Interview $^{41}$ mit dem chilenischen Journalisten Alberto Rojas Giménez, das in der chilenischen Tageszeitung El Mercurio am 23.11.1924 erschien. Hier wird er mit den Worten zitiert: «París, solo París es la ciudad en que se puede vivir dignamente». ${ }^{42}$ Im selben Interview wird er durch seinen Interviewpartner quasi als Fremd-

38 Erschienen in der ersten Nummer der Zeitschrift L’Esprit Nouveau (Oktober 1920). In: Vicente Huidobro: Obra poética, S. 1299-1301.

39 «Pour comprendre tout l'effort et le mérite énorme de ces poètes, il faut se rendre compte du milieu hostile dans lequel ils vivent. La moindre audace, la plus petite image sortant du cercle étroit dans lequel le public a l'habitude de se promener, provoquent des criailleries accompagnées de railleries et d'insultes» (Ebda., S. 1300).

40 «[...] je ne cherche d'ailleurs qu'à faire mieux apprécier le double effort que soutiennent aujourd'hui les poètes de langue espagnole. [...] dans les pays de langue espagnole, les artistes ne sont pas réunis comme ici en un grand centre, mails ils sont dispersés et et par cela même plus facile à être mis en déroute par les attaques de la sottise» (Ebda., S. 1300f.).

41 Sarabia (Rosa Sarabia: Eclipse de imagen: los poemas pintados de Vicente Huidobro. In: Vicente Huidobro: Obra poética. Herausgegeben von Cedomil Goic. Madrid u.a.: Colección Archivos 2003, S. 1430) deutet die Französisierung des Vornamens «Vicente» zu «Vincent» als Versuch Huidobros, zu Beginn der 1920er Jahre in Frankreich künstlerisch nachhaltig Fuß zu fassen.

42 Alberto Rojas Jiménez: Vincent Huidobro. In: Cecilia García-Huidobro (Hg.): Vicente Huidobro a la intemperie. Entrevistas (1915-1946). Santiago de Chile: Ed. Sudamericana 2000, S. 48-52, hier S. 50 . 
zuschreibung hybrid zwei Räumen zugeordnet: direkt im Eingangssatz wird er zunächst der französischen Nation zugeschlagen und als «poeta francés nacido en Santiago de Chile» bezeichnet, was vielleicht gar nicht unabsichtlich an die Biographie von Isidore Ducasse, Künstlername Lautréamont, in Montevideo geborener Sohn französischer Staatsbürger und wichtiger Referenzautor der Surrealisten erinnert. Gleich im Folgesatz wird er aber wieder unter die «artistas sudamericanos» eingeordnet. ${ }^{43}$

Das Interview zeichnet sich durch die direkte und indirekte Charakterisierung Huidobros als welterfahren aus, durch den Interviewer und den Autor selbst, der seine eigene Mobilität und Weltläufigkeit herausstellt, sich damit zum einen als nomadischer Künstler inszeniert, zum anderen ein (neues) Zentrum, nämlich Paris, angibt, und damit die Heimat, sein Herkunftsland Chile, erneut als peripher markiert: "Yo conozco todos los países de la tierra, he ido en todas las direcciones, y cada vez que me alejo de París, me alejo con dolor, y cada vez que vuelvo mi corazón tiembla, se estremece de alegría». ${ }^{44}$

Auch wenn Huidobro sich Paris als Zentrum emotional zuordnet, damit im Sinne Flussers zwar eine Freiheit von der alten Heimat an den Tag legt, aber zugleich neue Bindungen eingeht, so wehrt er sich zugleich vehement gegen den Vorwurf des «antipatriota», da er in französischen Anthologien als «poeta francés» erscheine, und beharrt auf seiner Zugehörigkeit zur chilenischen Nation, d.h. er situiert sich in einem räumlichen «Dazwischen». Der wahre Patriotismus bestehe doch darin, so Huidobro, die durch Kulturvergleich und eigene Mobilität erkannten Defizite beheben zu wollen: «dolerse de los defectos, llorar sobre los vacíos y anhelar y luchar para extinguir esos defectos». ${ }^{45}$ Denn im gleichen Inter-

43 Ebda., S. 48; vgl. auch Waldo Rojas: Huidobro a la hora de las vanguardias: acercamiento a su obra poética en francés, S. 471. In: Patricio Lizama/María Inés Zaldívar (Hg.): Las vanguardias literarias en Chile. Bibliografia y antología crítica. Madrid/Frankfurt a.M.: Iberoamericana/Vervuert 2009, S. 471.

44 Alberto Rojas Jiménez: Vincent Huidobro, S. 50. Den Abstand des Landes zu Trends und Entwicklungen im (europäischen) Zentrum und die Rückständigkeit und Provinzialität Chiles lässt er ebenfalls anklingen, wenn er akzentuiert: «¿No sabían esto en Chile? [...] Volver a Chile? [...] Sí, deseo ir, hacer un viaje» (ebda.), die deutlich macht, dass sich Huidobro offensichtlich fest(er) in Paris verortet und nur temporär in Chile.

45 Alberto Rojas Giménez: Vincent Huidobro, S. 50. Das hat die nationale chilenische Kritik irritiert, ihm Vorwürfe des (Vaterlands-)«Verrats» und eines «galicismo mental» eingebracht (vgl. Enrique Lihn: El lugar de Huidobro (1970). In: René da Costa (Hg.): Vicente Huidobro y el creacionismo. Madrid: Taurus 1975, S. 371, auch Daniel Balderston verweist darauf in «Huidobro and the Notion of Translatability»). Vgl. dazu auch José Alberto de la Fuente: Vicente Huidobro: el adelantado que no escuchamos. Santiago de Chile: Universidad Católica Silva Henríquez 2010, S. 105f., der sich mit dem politischen und sozialen Engagement des Dichters befasst, auch auf seine Aktivitäten und Einflüsse in den verschiedenen Ländern eingeht. $\mathrm{Zu}$ seiner Utopie «An- 
view kündigt er ein Buch zu Chile an - «Tierra Natal», nach aktuellem Stand nie erschienen - und entwirft das utopische Projekt eines neuen (Ideal-)Landes als (Re-)Migrationsphantasie. «(M)i querido Chile», müsse durch europäische Eliteneinwanderung verbessert werden, da es starke Defizite im Bereich der Künste aufweise:

Mi anhelo más alto es crear un país. [...] Llevar de acá, de Europa, la mejor gente, los mejores ingenieros, los mejores músicos, los más grandes arquitectos y los dos o tres únicos poetas que hoy existen, capaces de crear un país como los faraones crearon el Egipto. [...] No tenemos nada, ni arquitectura, ni música, ni poesía. ${ }^{46}$

Doch schneller als dieses Interview von November 1924 vermuten ließe, kehrt Huidobro im April 1925 nach Chile zurück, Ausdruck seiner privilegierten, «spielerischen Mobilität», um bei den Präsidentschaftswahlen, nominiert von der Federación de Estudiantes- erfolglos - zu kandidieren, und damit eventuell das zuvor angekündigte utopische Projekt umzusetzen. Medial flankiert wird diese Rückkehr durch ein Interview am 29.4.1925 in der Tageszeitung La Nación (Santiago de Chile), Titel «Con Vicente Huidobro», geführt von Jean Emar, dem Pseudonym des chilenischen Schriftstellers Álvaro Yáñez Bianchi. ${ }^{47}$ Ähnlich wie im Interview von 1924, noch nonkonformistischer (um nicht zu sagen unerträglich arrogant) und die eigene nomadische, grenzüberschreitende Freiheit noch stärker heraushebend, setzt der Autor nach sechs Jahren Abwesenheit von Chile Europa als hegemonialen Bezugspunkt. Er konstatiert «ningún adelanto», das Fortbestehen einer «idiotez reinante» und - auf die Dominanz der Jesuiten abhebend - einer «enfermedad mortal» ${ }^{48}$, die nur durch Einwanderung - und damit verbundener ethnischer Mischung - «blonden Blutes», so die kreationistische contradictio in adiecto, aus Nordeuropa zu beheben sei: «el grito de guerra de todo verdadero patriota debe ser: ahogar, confundir al criollo en sangre rubia del norte de Europa». ${ }^{49}$ Huidobro

desia» (1940/41) vgl. ebda., S. 75f., zu seinen politischen Aktivitäten in Chile und der Kandidatur für die Präsidentschaft ebda., S. 80-85.

46 Alberto Rojas Jiménez: Vincent Huidobro, S. 50.

47 Jean Emar: Con Vicente Huidobro. In: Cecilia García-Huidobro: Vicente Huidobro a la intemperie, S. 56-62, hier S. 56f. Dass das Französische als Prestigesprache auch spielerisch verwendet wird, und es gang und gäbe war, Künstlernamen zu verwenden, wird am Interviewer und späteren Schriftsteller Juan Emar ersichtlich: Er zeichnete zuerst mit Jean Emar - französisch ausgesprochen identisch mit «'en ai marre» («Ich habe genug»), typische Protesthaltung der Avantgarde der Zeit, später mit Juan Emar (vgl. Roberto Ángel: Juan Emar y la crítica. In: Hispamérica XLVII, 139 (2018), S. 97).

48 Jean Emar: Con Vicente Huidobro, S. 60.

49 Ebda. Die Mestizisierungsphantasien der mexikanischen Intellektuellen (José Vasconcelos: Raza cósmica) im gleichen Jahrzehnt gehen in eine andere Richtung. Huidobro scheint eher die 
schreibt dem nördlichen, «weißen» Europa (nicht dem mediterranen Teil) eine Rolle als «Entwicklungshelfer» für Chile zu und kritisiert zugleich die «kulturelle Verspätung» und fehlende Originalität der «artes y letras suramericanas», ${ }^{50}$ sich selbst natürlich ausnehmend.

Ein weiterer Aspekt von Huidobros Identitätskonzept findet sich im Vorwort zu seinem ersten Roman, Mio Cid campeador von 1929, einem Werk, das den spanischen mittelalterlichen Nationalhelden in eine ferne Zukunft versetzt. ${ }^{51}$ Dieses Vorwort enthält einen auf November 1928 datierten Brief an einen der populärsten Hollywoodschauspieler der Zeit, Douglas Fairbanks, der Interesse für die Hauptrolle des Cid gezeigt habe. Um diesem den Stoff und die Rolle schmackhaft zu machen, spricht Huidobro nun von «nuestro Cid», der Heroen wie Hernán Cortés, dem Gran Capitán, Pizarro und den Brüdern Pinzón vergleichbar sei. ${ }^{52}$ Die eigene Zuordnung und Identifikation erfolgt hier zu einem imperialen Spanien der Entdeckung und Expansion, ohne ein offensichtliches kolonial- und spanienkritisches Bewusstsein, wie es im Kuba der 1890er Jahre bei José Martí, im Werk von José Rodó und besonders im Mexiko nach der Revolution an der Tagesordnung war. ${ }^{53}$ Die «großen Männer», die Huidobro in seinem Brief anführt, sind alle Spanier. Allerdings ist auch ein merkantiler Aspekt von Huidobros Bestreben (und der Avantgarde insgesamt) nach internationaler Sichtbarkeit, adressiert hier an einen der berühmtesten Schauspieler der Zeit in einem männlich-weiß-dominierten Hollywood, das in Hauptrollen auf eben solche Schauspieler setzt, nicht unberücksichtigt zu lassen. ${ }^{54}$

den Cono Sur prägenden - gescheiterten - Einwanderungsphantasien der Argentinier aus der 2. Hälfte des 19. Jahrhunderts aufzugreifen, die mit Einwanderungsbüros in Europa versuchen, Mittel- und Nordeuropäer zu rekrutieren.

50 Jean Emar: Con Vicente Huidobro, S. 60f.

51 Vgl. Ana Pizarro: Huidobro: noticias del futuro und Rosa Pellicer: La tradición en la vanguardia. Mío Cid Campeador de Vicente Huidobro. In: Anales de Literatura Hispanoamericana 26 (1997), S. 485-495.

52 So auch in seinem Artikel Espagne. In: L'Esprit Nouveau 18 (1923), vgl. Vicente Huidobro: Mio Cid Campeador. México: Universidad Autónoma Metropolitana 1997, S. 17.

53 Was eine andere Kolonialmacht, nämlich das britische Empire angeht, hatte Huidobro offensichtlich diesen kritischen Blick, wie er in seinem französischsprachigen Essay Finis Britannia (sic), erschienen in Paris (Fiat Lux) von 1923 darlegt.

54 Unter postkolonialen Gesichtspunkten ist interessant, dass das Filmthema des Cid in Hollywood allerdings nicht mit Douglas Fairbanks, sondern erst 1961 mit Charlton Heston und Sophia Loren, gedreht im Spanien Francos, umgesetzt wurde. Es gibt jedoch eine Verfilmung zur Eroberung Mexikos durch Cortés, gespielt von Tyrone Power (gleicher Typus des Swashbuckler wie Fairbanks), von 1947, basierend auf dem historischen Roman Captain from Castile (1944) des USAmerikaners Shellabarger, in dem kurz nach dem Zweiten Weltkrieg Amerika gegenüber einem rigiden, verknöcherten, in Konventionen und Kastendenken erstarrten Europa (Spanien) als Ort 
Insgesamt zeigen die Interviewäußerungen Huidobros zwischen 1919 und 1925, dass er, basierend auf seiner privilegierten Mobilität und dem in Szene gesetzten Nomadismus, keine eindeutige Zugehörigkeit des Migranten, sprich keine Zuordnung seiner selbst vornimmt: zum einen schätzt er die Kultur seines Herkunftslandes gering und orientiert sich explizit an Paris und (Nord-)Europa als kultureller Hegemonialmacht und Metropole, zum anderen versucht er den Anschluss an die nationale imaginierte Gemeinschaft Chile zu halten. Schließlich, ab Mitte der 1920er Jahre, evoziert er eine spanischsprachige, auf dem Kolonialreich basierende Gemeinschaft, der er sich als Kunstschaffender zugehörig fühlt, und grenzt sich von dem «Nördlichen» eher ab. Eine Freiheit von Bindungen an Heimat oder Heimaten, wie sie Flusser in seinem Spätwerk als erstrebenswerten Zustand formuliert, ist hier m. E. nicht zu erkennen.

Noch ambiger wird das Bild der Zugehörigkeit des Migranten, wenn wir Huidobros Publikationsstrategien der 1910er und 1920er Jahre in den Blick nehmen, die nicht nur mit Aneignung der Hegemonialsprache Französisch und Erschließung eines anderen, aufgeschlosseneren Publikums, sondern auch mit einem Kampf um Originalität und Urheberschaft zu tun haben.

\section{II.b Huidobros Publikationsstrategien - Aneignung der Hegemonialsprache und Kampf um Originalität oder: «An artist who cannot speak [French] is no artist»}

Die Zugehörigkeit des künstlerisch und kreativen Migranten Huidobro erstreckt sich auch auf die Frage, in welcher Sprache er in der (aufnehmenden) Mehrheitsgesellschaft tätig ist oder sein muss, um Aufmerksamkeit zu erlangen und sich Gehör zu verschaffen. Das zielt ab auf die Frage nach einer bzw. der hegemonialen Sprache der Pariser Avantgarden, die zu der Zeit nicht explizit adressiert wurde. Statt «An artist who cannot speak English is no artist» (1994), wie es der kroatische Künstler Mladen Stilinovic 1994 provozierend und plakativ formuliert (wiederaufgenommen in der Ausstellung «Hello World. Revision einer Sammlung» im Hamburger Bahnhof, Berlin im Juni 2018), müsste für das Paris der 1910er und 1920er Jahre wohl Englisch durch Französisch ersetzt werden. Vorschub geleistet wurde dieser Tendenz für die hispanoamerikanischen Literaten Ende des 19. und Anfang des 20. Jahrhunderts dadurch, dass das Französische

der Freiheit entworfen wird (vgl. Verena Dolle: Amerika als Ort der Freiheit? Die Eroberung Mexikos als Erinnerungsort in «Captain from Castile» (USA, 1947). In: U. Fendler/M. Wertheim (Hg.): Entdeckung, Eroberung, Inszenierung. Filmische Versionen der Kolonialgeschichte Lateinamerikas und Afrikas. München: Meidenbauer 2007, S. 27-52. 
als Literatursprache einen sehr hohen Stellenwert genoss, der sich in häufigen Rekursen und seiner Verwendung als «Einbettungssprache» in literarischen Werken zeigt. ${ }^{55}$ Die Avantgarden sind multinational und polyglott, mit kosmopolitischen Anspruch. Migranten wie der gebürtige Rumäne Tzara publizieren auf Französisch, der gebürtige Elsässer Hans Arp auf Deutsch und Französisch, der Italiener Marinetti auf Französisch. ${ }^{56}$

Huidobro geht aber weiter. Denn er publiziert seine Gedichtbände wie auch Manifeste mit der Ankunft in Paris auf Französisch (zwischen 1917 und 1925) und dann, von ihm selbst übersetzt, auch auf Spanisch, versucht also, sich zwei kulturelle Räume zu erschließen. ${ }^{57}$

Die Publikation von Lyrik in einer Fremdsprache, die Huidobro nach eigenem Bekunden zumindest bei seiner Ankunft in Paris nicht gut beherrschte, ${ }^{58}$ hat die Forschung nachhaltig beschäftigt. In der Regel wird sie als Mischung aus Anpas-

55 Vgl. Marcos Eymar Benedicto: La poética de la autotraducción en tres escritores bilingües franco-hispánicos: Vicente Huidobro, Juan Larrea y Ventura García Calderón. In: Pierre Civil/ Françoise Crémoux (Hg.): Actas del XVI Congreso de la Asociación Internacional de Hispanistas: Nuevos caminos del hispanismo. París, del 9 al 13 de julio de 2007. Madrid/Frankfurt: Iberoamericana/Vervuert 2010; Marcos Eymar Benedicto: La langue plurielle. Le bilinguisme franco-espagnol dans la littérature hispano-américaine (1890-1950). Paris: Harmattan 2011; Werner Helmich: Ästhetik der Mehrsprachigkeit. Zum Sprachwechsel in der neueren romanischen und deutschen Literatur. Heidelberg: Universitätsverlag Winter 2016, S. 306.

56 Vgl. Octavio Paz: Los hijos del limo, S. 164f.

57 Die Werke von Huidobro sind von 1917 bis 1931 bis auf den Essayband Vientos contrarios (1926) in Europa erschienen, darunter vier Gedichtbände zuerst auf Französisch. Ab 1934 erscheinen seine Werke in Chile. Das zweisprachige, in Frankreich, Spanien und Chile erschienene Werk hat zu dem Lamento geführt, dass die Internationalisierung (die Erschließung eines anderen Publikums) die nationale Wirkung eingeschränkt habe (vgl. Cedomil Goic: Cronología, XXI). Padilla (José Ignacio Padilla: El terreno en disputa es el lenguaje, S. 214) sieht Huidobros Französischkenntnisse skeptisch («no domina el francés») und vertritt die Ansicht, dass die Gedichte keine echten Übersetzungen seien, sondern eher eine «recomposición espacial que debilita su referencialidad». Er bezieht sich dabei auf verschiedene Versionen des Gedichts «Otoño» aus Espejo de agua und Horizon carré 1917, zuerst erschienen in Nord-Sud Nr. 3. Vgl. dazu auch Marcos Eymar Benedicto: La poética de la autotraducción en tres escritores bilingües franco-hispánicos: Vicente Huidobro, Juan Larrea y Ventura García Calderón und Daniel Balderston: Huidobro and the Notion of Translatability.

58 Es sind Autographe mit handschriftlichen Korrekturen von ihm selbst bzw. Juan Gris erhalten, der seit 1906 in Paris war und ihm bei der Abfassung/Übersetzung der Gedichte ins Französische anfangs geholfen hat, so dass der Schaffensprozess nachvollziehbar wird (vgl. Waldo Rojas: En torno a Automne régulier y Tout à coup; Waldo Rojas: Huidobro a la hora de las vanguardias: acercamiento a su obra poética en francés, Daniel Balderston: Huidobro and the Notion of Translatability und Marcos Eymar Benedicto: La poética de la autotraducción en tres escritores bilingües franco-hispánicos: Vicente Huidobro, Juan Larrea y Ventura García Calderón; Marcos Eymar Benedicto: La langue plurielle). 
sungsstrategie an die Mehrheitsgesellschaft und poetologischem Anspruch gedeutet. $^{59}$ Es lässt sich aber auch sagen, dass Huidobro sich mit einer gewissen Naivität oder Chuzpé die hegemoniale Sprache Französisch aneignet, also zu seiner (bzw. einer seiner) eigenen macht und sich von Beginn seines Aufenthalts in den kulturellen Raum einschreibt, ohne auf akademische Befindlichkeiten, Vorschriften und Codes zu achten. Diese etwas hemdsärmelige, auf jeden Fall nicht sprachautoritätshörige und dem Duktus der Ruptur entsprechende Herangehensweise flankiert und unterfüttert er poetologisch, indem er das Gedicht in seiner Bildhaftigkeit für universal übersetzbar und sprachliche Oberflächen dementsprechend für weniger wichtig erklärt. Damit verschafft er sich einen kreativen Freiraum, der die Dominanz einer bestimmten Sprache von vornherein nicht akzeptiert.

Ein weiterer Punkt, der ebenfalls unter dem Aspekt der Publikations«strategie» Huidobros gefasst werden kann, aber aus meiner Sicht mit seiner Position eines aus der Peripherie kommenden Migranten in einer Mehrheitsgesellschaft zu tun hat, ist die zu Beginn der 1920er Jahre erbittert geführte Diskussion, ob Pierre Reverdy oder Huidobro die Urheberschaft am «creacionismo» zuzuschreiben sei.

Ohne Zweifel empfängt Huidobro Inspirationen aus dem künstlerischen Schmelztiegel Paris der 1910er und 20er Jahre und der dort entstehenden internationalen kulturellen Avantgarde, gerade was den literarischen Kubismus, die Frage danach, wie Literatur und Poesie Simultanität statt Nachzeitigkeit beschreiben kann, die Autonomie des Gedichts als Objekt angeht. ${ }^{60}$ Doch beansprucht er mit dem Ankommen auf europäischem Boden sogleich für sich, dass er seine Poetik, damit auch den creacionismo, schon in Lateinamerika entwickelt und von dort aus nach Europa mitgebracht habe. Deutlich wird dies im mit Ángel Cruchaga geführten Interview während seiner Chilereise vom 31.8.1919 sowie in seinem bereits genannten Aufsatz zur «Littérature de la langue espagnole d'aujourd'hui» von $1920 .^{61}$ Als Beleg für die eigene Urheberschaft des creacionismo verweist der

59 Vgl. Carlos Démaso Martinez/Andrea Ostrov: Bilingüismo y vanguardia en Vicente Huidobro. (S. Fußnote 21).

60 Vgl. Paz, Octavio: Los hijos del limo. Del romanticismo a la vanguardia. Barcelona: Seix Barral 31990 (Biblioteca de Bolsillo).

61 Huidobro formuliert zwar zuerst einmal - in Form eines klassischen Bescheidenheitstopos seine relative Unkenntnis der aktuellen literarischen Szene in Lateinamerika und Spanien, gibt dann aber doch Auskunft über zwei Strömungen, v.a. die Kreationisten, die er sowohl für Spanien als auch für Lateinamerika auf seine eigene Urheberschaft, seinen Vortrag in Buenos-Aires 1916 zurückführt (vgl. Vicente Huidobro: Obra poética, Herausgegeben von Cedomil Goic. Madrid u. a.: Colección Archivos 2003, S. 1299f.). Bemerkenswerterweise ist der einzige chilenische Autor, den Huidobro in diesem Artikel außer sich selbst überhaupt namentlich erwähnt, sein Interviewpartner von 1919, Ángel Cruchaga. 
Chilene auf seinen Vortrag, den er in Buenos Aires 1916, vor der Abreise nach Europa, gehalten hat - erst Jahre später publiziert - sowie seinen angeblich 1916 erschienenen ersten kreationistischen Gedichtband Espejo de agua. ${ }^{62} \mathrm{Um}$ das Erscheinungsjahr dieses Bandes hat es lange Zeit Unklarheit (da sich kein Band mit dem Erscheinungsort und -jahr in Argentinien bibliographisch nachweisen ließ) und Polemik gegeben, da Huidobro von Seiten der Reverdy-Anhänger bewusste Täuschung vorgeworfen wurde. Der jetzige Erkenntnisstand ist, dass der Band allem Anschein nach auf Betreiben des Autors mit Absicht rückdatiert und erst 1918 in Madrid mit verschiedenen Auflagenangaben gedruckt wurde, die Reverdy-Seite also recht hatte. ${ }^{63}$

Vor dem Hintergrund dieses hartnäckig verfochtenen Anspruchs, sich selbst um jeden Preis als alleinigen Schöpfer des creacionismo zu präsentieren und den Bezug zu anderen, namentlich Reverdy, etwas vage als «analogía espiritual» ${ }^{64} \mathrm{zu}$ bezeichnen, erscheinen auch die wenigen Verweise auf das indigene und multiethnische Amerika in einem neuen Licht. ${ }^{65}$ 1921, in dem ästhetischen Manifest «La création pure. Propos d'esthétique», ${ }^{66} 1925$ in seinen Band Manifestes aufgenommen, verweist Huidobro auf den südamerikanischen, indigenen Ursprung dieser Idee der autonomen, nicht an der Natur mimetisch orientierten Schöpfung: «Cette idée de l'artiste créateur absolu, de l'Artiste-Dieu, me fut suggérée par un vieux poète indien de l'Amérique du Sud (Aimara) [...]». ${ }^{67}$ Im Kontext der Diskussion um die Frage nach Originalität der Ideen versucht er also, die eigene Position zu stärken und die Idee eines europäischen, französischen Ursprungs zu entkräften.

Auch im oben bereits angesprochenen Interview von 1925 mit Jean Emar verweist er wieder auf seine Poetik des creacionismo als neuartig und originell. Nach seiner Einschätzung der zeitgenössischen Kunst in «esa Europa», in Dichtung, Prosa, Malerei, Bildhauerei, Architektur, verdienten es nur wenige Namen, so Huidobro, genannt zu werden: nämlich Tzara, Eluard, Arp, sowie Juan Larrea und Gerardo Diego (vgl. Jean Emar: Con Vicente Huidobro, S. 58), die er als seine Schüler in Spanien ansieht und die ihn im Streit um die Urheberschaft des creacionismo verteidigen.

62 Vgl. Ángel Cruchaga: El creacionismo y sus apóstoles en Europa. In: Cecilia García-Huidobro, Vicente Huidobro a la intemperie, S. 32-40, hier S. 38f.

63 Vgl. hierzu Cedomil Goic: Introducción (El espejo de agua). In: Vicente Huidobro: Obra poética. Herausgegeben von Cedomil Goic. Madrid u.a.: Colección Archivos 2003, S. 379f. und S. 384-389; Waldo Rojas: Huidobro a la hora de las vanguardias: acercamiento a su obra poética en francés; Marcos Eymar Benedicto: La langue plurielle.

64 Ángel Cruchaga: El creacionismo, S. 38f.

65 Allein der nordamerikanische weiße «Cow-boy» wird zum literarischen Sujet, nicht die Ureinwohner Amerikas wie etwa die chilenischen Araukaner.

66 Zuerst erschienen im 7. Heft von L'Esprit Nouveau, dann als Vorwort in den im gleichen Jahr auf Französisch erschienenen Gedichtband Saisons choisies aufgenommen.

67 Vicente Huidobro: Obra poética, S. 1304. 
Das gleiche Ziel, nur mit anderen Argumenten, findet sich auch noch in einem weiteren Manifest Huidobros, «La poésie des fous», ebenfalls 1925 in seinen Manifestes in Paris erschienen. Hier grenzt sich der Autor deutlich von Bretons erstem Manifest des Surrealismus von 1924 mit dessen Betonung des Unbewussten und des psychischen Automatismus $a b^{68}$ und kommt auf sein eigenes künstlerisches Schaffen zu sprechen. Nun evoziert er das Schöpfen aus dem Fundus einer «mémoire ancestrale» gegenüber einer «mémoire actuelle», wobei er erstere den Menschen aus dem Mittelmeerraum und letztere dem «Norden» (wohl dem Norden Europas und damit impliziert auch Frankreich) zuschreibt: «C'est le case [sic] des meridionaux et des hommes du Nord». ${ }^{69}$ Die «mémoire ancestrale» sei diejenige, «qui fait la différence des facilités de certaines races pour certains arts. [...]», vor allem bei einer «race des peintres», die Vorteile habe gegenüber einem Künstler, der nur aus einer «mémoire actuelle» schöpfe. ${ }^{70}$ In einer retrospektiven Verknappung von Alternativen und historischen Entwicklungen versucht er, mit einem im Trend der Zeit liegenden essentialisierenden Zugriff ${ }^{71}$ künstlerische Innovation ethnisch kausal zu erklären:

Seulement un homme comme Picasso, andalou, mélange d'arabe et de celte ou latin, pouvait inventer le cubisme. Ces [sic] ancêtres arabes n'aimaient pas la représentation de l'objet, et son éducation la lui montrait partout. De ce conflit entre sa mémoire ancestrale et sa mémoire acquise devait jaillir sa peinture, ce conflit devait être la première source d'une esthétique nouvelle, au moyen de laquelle il chercherait à s'évader de l'objet sans réussir pleinement, à cause peut-être de la force de sa latinité et de sa mémoire actuelle. ${ }^{72}$

Dies ist eine recht eigenwillige Erklärung für innovatives Schaffen, die auf Prämissen des 19. Jahrhunderts, den Naturalismus Tainescher Prägung, als Kunst bestimmende Faktoren - race, milieu und moment - verweist und den esoterischen, aus der Astrologie stammenden Begriff des Ahnengedächtnisses bemüht. Das Manifest schließt mit dem Verweis auf das eigene, Picasso vergleichbare Schaffensziel, die Kunst aus dem Dienst der Repräsentation zu befreien und hebt, wie immer in den poetologischen Texten Huidobros, (geradezu obsessiv) die eigene Originalität und Eigenständigkeit hervor, die er nun aber an ein hispanisches, mediterran fundiertes Kollektiv anbindet: «En poésie, sans connaître

68 «Moi aussi, je proclame l'inconscient mais l'inconscient des hommes conscients» (Vicente Huidobro: Obra poética, S. 1352).

69 Ebda.

70 Ebda.

71 Der Verweis auf das Mediterrane findet sich auch noch in Carpentiers Identitätskonzept eines essentialistischen, gleichwohl mestizischen Ideals in Los pasos perdidos (1951) wieder.

72 Vicente Huidobro: Obra poética, S. 1352. 
Picasso, j'avais toujours eu la même obsession, originée sûrement par les mêmes causes ancestrales». ${ }^{73}$ Huidobro präsentiert sich - mit Verweis auf den 1925 bereits sehr erfolgreichen, aus Málaga stammenden Picasso, was die Universalität der Literatur und der Malerei suggeriert - mit mediterraner, arabisch-lateinischer Abstammung (also ohne indigenen Einfluss), ohne zwischen Spanien/Europa und Lateinamerika zu unterscheiden, ähnlich wie dann wenige Jahre später im Brief an Fairbanks (s.o.).

Dieser Verweis lässt sich m.E. deuten als Versuch Huidobros, die seit 1920 erhobene Streitfrage im europäischen Raum um Originalität und Urheberschaft des creacionismo anders aufzustellen, weg von individuellen Argumenten, und gegenüber dem «moment», den zeitlichen näheren Umständen, essentialisierende Gründe anzuführen und damit seine Position zu stärken.

Über individuelle Animositäten von Männern mit bestimmter, egozentrischer oder narzisstischer Persönlichkeitsstruktur und dem etwaigen Streit über die Zeitschrift Nord-Sud (die Huidobro finanzierte) hinaus lässt sich diese Diskussion und die Argumentation Huidobros, der sich unter starkem Rechtfertigungszwang sieht, wie seine immer wiederkehrende Verweise auf das eigene Schaffen deutlich machen, repräsentativ deuten: nämlich als Auseinandersetzung zwischen hegemonialem kulturellen Zentrum und kolonialer Peripherie. Das Paris der 1910er und 20er Jahre fungiert, wie bereits erwähnt, als dialogischer Resonanzraum für künstlerische Begegnungen, eben auch für Huidobro, in dem die eigenen bereits vorhandenen Ideen sich weiterentwickeln, wie Rojas ausführt:

lo que permitirá a su genio impregnarse de aquellos recursos en sus mejores opciones y si no llevarlos a la perfección, como el poeta presume, por lo menos sintetizarlos progresivamente en una ecuación personal, cuya intuición y vislumbres traía Huidobro desde Chile. ${ }^{74}$

Rojas spricht zwar von einem in Paris praktizierten «cosmopolitismo cultural», aber zugleich auch vom Anspruch auf «originalidad a ultranza». ${ }^{75}$ Dieser Resonanzraum ist also kein herrschaftsfreier, sondern ein von Hierarchien durchzogener Raum, in dem Ein- und Ausschlüsse vorgenommen werden.

\section{Zwischenfazit}

Was die Zugehörigkeiten des Migranten Huidobro angeht, die er in seinen faktualen Texten formuliert, so ergibt sich für die Zeit zwischen 1919 und 1929 kein

73 Ebda., S. 1353.

74 Waldo Rojas: Huidobro a la hora de las vanguardias, S. 475.

75 Ebda., S. 475; vgl. auch S. 479; José Ignacio Padilla: Vicente Huidobro: Entrar y salir del lenguaje, S. 213. 
klares Bild, sondern ein situationsabhängiges Changieren zwischen Positionen: Huidobro äußert Widerstand gegen ein als kulturell rückständig empfundenes Vaterland Chile (Nation/race) mit einer starren Oberschicht (class), durchaus begleitet von einem gewissen Minderwertigkeitsgefühl und «inkongruentem Verhalten ${ }^{76}$, schlägt als Lösung nordeuropäische Einwanderung «blonden Blutes» kreativer Menschen vor, verwendet Anfang der 1920er Jahre einen französisierten Vornamen. Doch mit dem Widerstand gegen seine Person bzw. seinen Anspruch auf alleinige Urheberschaft des creacionismo, was einem Ausschluss aus der Gemeinschaft der internationalen Avantgardisten in Paris gleichkommt, konstruiert er sich ab 1925 als Teil einer mediterranen spanischsprachigen Gemeinschaft, die produktiv(er) und fruchtbar(er) als der Norden sei. Erkennbar wird, wie schwer es ihm gefallen ist, den Anspruch auf avantgardistische Urheberschaft einzufordern und dafür anerkannt zu werden (und welche Mittel er dafür ergreift). Im folgenden, letzten Abschnitt soll nun untersucht werden, wie die Erfahrung von Mobilität, Fremdheit und Nicht-Zugehörigkeit von Huidobro im Werk poetologisch gewendet und fruchtbar gemacht wird.

\section{Von der Freiheit des Werks: Unendliche Übersetzbarkeit und die Poetik der Fremdheit: «una lengua que no sea materna»}

\section{III.a Übersetzbarkeit}

Die Mobilität von Huidobro als Person mündet in (oder weniger kausal: lässt sich rückbinden an) eine kontinuierliche Inszenierung des lyrischen Ichs als global Reisender mit entsprechend hoher Mobilität durch unterschiedliche, moderne Verkehrsmittel. Dies lässt sich häufig in dem Gedichtband Ecuatoriale beobachten, in dem er viel auf räumliche Bezüge und Bewegungen zwischen Europa, Nord- und Südamerika eingeht, per Schiff, etwa in «Globe-trotter» (zuerst publiziert in der Zeitschrift La Bataille Littéraire 1920, dann im Gedichtband Automne régulier 1925, über Beziehung zu imaginiertem, geographisch auf dem Festland verorteten weiblichen $\mathrm{Du}$ ) oder per Automobil in «Hp». Eine der wenigen Stellen, die sich biographisch auf den Dichter Huidobro beziehen lassen, so Goic, findet sich im Gedicht «Poète» aus Automne régulier (1925), wenn es heisst: «J'ai la flûte

76 So kritisch sieht es Lihn (Enrique Lihn: El lugar de Huidobro (1970), S. 376f.). 
officielle du chérubin sauvage». ${ }^{77}$ Es verweist damit auf eine jahrhundertelange, bei Vespucci beginnende Fremdzuschreibung des Amerikaners als «Wilder», die durch den Zusatz des christlich konnotierten, abendländischen Engels (Cherubim) oxymoronhaft aufgebrochen wird, und markiert die Position des lyrischen Ichs als exzentrisch.

Der wichtigste Punkt für Huidobros Poetik der 1920er Jahre ist der Anspruch, Poesie als universale Kunst der Malerei oder Bildhauerei vergleichbar zu verstehen; weniger auf Stil und Geschliffenheit des Ausdrucks, auf sprachspezifischen Rhythmus und Klang als vielmehr auf die Originalität der kreationistischen Bilder zu achten und sich damit unabhängig von bestimmten Sprachoberflächen zu machen. In diesem Sinne ist es nur konsequent, dass er eine universale Übersetzbarkeit von Poesie postuliert, da es auf die im Text kreierten Bilder («hechos nuevos», neue, nicht mimetische Tatsachen), ankomme, so in seinem Manifest «Le créationnisme» (1925):

Si pour les poètes creationnistes ce qui est important est la présentation du fait nouveau, la poésie créationniste devient traduisible et universelle car les faits nouveaux restent les mêmes dans toutes les langues. [...] quand l'importance du poème tient avant tout à l'objet créé il ne perd dans la traduction rien de sa valeur essentielle. ${ }^{78}$

Mit diesem durchaus auch strategisch motivierten Postulat senkt Huidobro die Hürde für das eigene dichterische Schaffen in einer ihm relativ fremden Sprache, unterläuft von vornherein Kritik von Seiten der französischen native speaker, die Sprache nicht zu können, von der er - vielleicht auch das ein Bescheidenheitstopos - sagt, dass er sie anfangs nur «gestammelt» habe ${ }^{79}$ und versucht sich die Aufmerksamkeit des französischen Publikums zu sichern. Gleichzeitig ist zu sagen, dass Huidobro - aus der südamerikanischen Peripherie kommend - sich auf diese Weise ohne größere Bedenken und Skrupel die Sprache des Anderen aneignet, sie zu seiner eigenen Literatursprache macht und zwei Korpora von je einsprachigen Gedichten kreiert. ${ }^{80}$

77 Vicente Huidobro: Obra poética, S. 631, ebda., S. 661.

78 Ebda., S. 1332; auf Spanisch erst 1945 publiziert, vgl. Cedomil Goic: Introducción (Manifiestos). In: Vicente Huidobro: Obra poética. Herausgegeben von Cedomil Goic. Madrid u.a.: Colección Archivos 2003, S. 1292; Carlos Démaso Martinez/Andrea Ostrov: Bilingüismo y vanguardia en Vicente Huidobro, S. 214; Daniel Balderston: Huidobro and the Notion of Translatability, S. 62f.

79 Vgl. Waldo Rojas: Huidobro a la hora de las vanguardias, S. 478 und Nr. 17.

80 Vgl. Jacques Derrida: Le Monolinguisme de l'autre. Ou la prothèse d'origine. Paris: Ed. Galilée 1996; Marc Crepón: Ce qu'on demande aux langues (autour du Monolinguisme de l'autre). In: Raisons politiques 2 (2001), S. 27 f. Es liegt auf der Hand, dass dieser Anspruch starke Aufmerksamkeit der Kritik bekommen hat. Den Dichter beim Wort nehmend, analysiert Balderston vier Gedichte unter dem Aspekt ihrer Übersetzbarkeit und konstatiert, dass jener bestimmte schwierig 
Auch wenn der Gedanke bei einem sich derartig in zwei sprachlichen Räumen bewegenden Dichter aus heutiger Sicht naheläge, so ist gerade deshalb anzumerken, dass Huidobro in den lyrischen Werken der 1910er und 1920er Jahre keine französisch-spanische Mehrsprachigkeit und kein Code-Switching zu ästhetischen kreativen Zwecken einsetzt. ${ }^{81}$

Mehrsprachigkeit wird allerdings explizit im Vorwort zu seinem auf Spanisch erschienenen Roman Hazaña de Mío Cid campeador von 1929 adressiert. Hier heißt es:

Encontrará el lector en este libro algunos galicismos y americanismos tanto en palabras como en giros. No me disculpo por ellos. Los empleo por una simple razón de antojo. Me place decir el volantín en vez de la cometa, porque encuentro más hermoso ese chilenismo que la palabra castiza cometa y más natural que pandorga o birlocha. Asimismo, respecto a algunos giros afrancesados, me place dejarlos y los dejo. [...] Si los clásicos llenaron nuestra lengua de italianismos, ¿quién puede decirnos algo a causo de nuestros galicismos? ${ }^{82}$

Es geht also nun nicht mehr nur um Übersetzbarkeit eines Werks, um sprachliche Grenzen zu überwinden und auf eine universale Poesie abzuzielen, sondern um die Hybridisierung der Sprache selbst, konkret des Spanischen, womit er jedoch, wie sich zeigen wird, auf das Gleiche, die Universalität der Poesie, abzielt. Huidobro wendet sich gegen eine sprachliche «Reinheit» und plädiert für Durchmischung, mit der die offensichtlichen Gallizismen und Amerikanismen (womit

zu transferierende Aspekte wie Paronomasien, klangliche und rhythmische Schwierigkeiten zwar vermeide, aber dass es letztendlich nicht so leicht sei wie postuliert (vgl. Daniel Balderston: Huidobro and the Notion of Translatability, S. 65f.). Eymar hat herausgearbeitet, dass Huidobro in seinen auto-traducciones aus dem Französischen ins Spanische näher am Französischen bleibt - also eher dezentriert als naturalisiert vorgehe und zugleich eine «re-escritura», ein Wieder-Schreiben praktiziert: ausdünnt, verändert, anpasst (vgl. Marcos Eymar Benedicto: La poética de la autotraducción en tres escritores bilingües franco-hispánicos: Vicente Huidobro, Juan Larrea y Ventura García Calderón, S. 124 und 127).

81 Mehrsprachigkeit wird hier nach Helmich (Werner Helmich: Ästhetik der Mehrsprachigkeit, S. 14-17) verstanden als bezogen auf das Werk, nicht auf die Fähigkeiten von Sprechern. CodeSwitching, der Wechsel von einer zu einer anderen Sprache zwischen oder innerhalb von Sätzen findet sich bei Huidobro nicht, anders etwa als es J.F.A. Oliver in seinem Band Gastling zu Migration und Fremdheitserfahrung praktiziert, der z.B. mitten in einer Zeile vom Spanischen ins Deutsche oder andersherum wechselt und Homophonien als kreatives Prinzip nutzbar macht (etwa in der Zeile «aus sprachenhäuten/hoy ein heute.» José F.A. Oliver: Gastling, S. 24); auch anders als etwa Rafael Alberti, Mitglied der generación del 27 in seinem berühmten Migrantengedicht «Vida bilingüe de un refugiado español en Francia», das über die Zweisprachigkeit die schwierige Exilsituation, Momente des Nicht-Verstehens und der Bedrohung thematisiert. Vgl. dazu Werner Helmich: Ästhetik der Mehrsprachigkeit, S. 156-159 und S. 486f.

82 Vicente Huidobro, Mio Cid Campeador, S. 20f. 
hier konkret Chilenismen gemeint sind) legitimiert werden. Anders als in den oben behandelten Äußerungen zur Zugehörigkeit des Migranten (s.o.), in denen Chile als defizitär charakterisiert wurde, markiert das Sprecher-Ich nun - eventuell auch aufgrund seines mehrjährigen Aufenthalts in Chile (mit dem gescheiterten Ausflug in die Politik) - selbstbewusst genau diese Herkunft und führt ästhetische, subjektive Gründe für die Verwendung von «Amerikanismen» an. Um den Rekurs auf Gallizismen, die er bereits in seinen auto-traducciones von Gedichten der 1910er und frühen 1920er Jahre verwendet und die sich als Beleg der Prestigeträchtigkeit des Französischen deuten lassen, argumentativ zu stützen, verweist er auf die Sprachgeschichte Spaniens, die sich seit der Renaissance bei einer anderen Prestigesprache, dem Italienischen, bedient habe.

Ohne es explizit zu machen, greift Huidobro in diesem Vorwort, das während seines zweiten Paris-Aufenthalts (1928-1932) entstanden ist, eine in der lateinamerikanischen Avantgarde geführte Diskussion und Bewusstwerdung um Sprache und Kanon, um «Reinheit der Sprache», die Frage nach Lokalkolorit und criollismo oder Kosmopolitismus auf. ${ }^{83}$ Er reisst zudem die Frage von Macht und Hierarchie an, nämlich welche Institution über ein literarisch angemessenes, traditionell europäisches, also hegemonial dominiertes Register und über die Qualität der entsprechenden Werke überhaupt $\mathrm{zu}$ entscheiden habe. Darüber hinaus greift der Chilene Huidobro ein zutiefst spanisches, mittelalterliches Sujet auf, den Cantar del mío Cid, aktualisiert es, eignet es sich thematisch, stilistisch und erzähltechnisch an und schreibt es unter Verwendung neuer, filmischer Schreibweisen um. ${ }^{84}$ Zum einen geht er damit mit der spanischen Avantgarde der Generación del 1927 konform, die einen Rückgriff auf nationale Traditionen prak-

83 Borges wandte sich in den 1920er Jahren dem Lokalen, dem criollismo zu und schrieb dezidiert in einem argentinisierten Spanisch, Huidobro dem Kosmopolitischen, aber mit hybridisierenden Tendenzen (vgl. Octavio Paz: Los hijos del limo; s.u. Fußnote 83). Die brasilianischen AvantgardeManifeste des modernismo «Pau Brasil» (1924) und «Manifesto antropófago» (1928), der Gedichtband Pau Brasil (1925) von Oswald de Andrade sowie der Roman Macunaíma (1928) von Mario de Andrade propagieren in einem postkolonialen Gestus die (metaphorische) Einverleibung und Aneignung des Fremden, auch der fremden Sprache, was deren Hybridisierung mit einschließt. Vgl. hierzu Maria Rosa Duarte de Oliveira, A representação do africano na literatura brasileira: a poesia Pau-Brasil de Oswald de Andrade. In: Verena Dolle/Helena Bonito Pereira u.a. (Hg.) Migrações literárias e artísticas: África - Brasil - Europa. Berlin: Peter Lang 2018, S. 121-130, v.a. S. $122 \mathrm{f}$.

84 Nach Ana Pizarro praktiziert Huidobro in Mío Cid campeador eine «time-space-compression», in der der Cid als eine Art ready made in ein fortgeschrittenes 20. Jahrhundert gesetzt werde (Ebda., S. 452), ebenso eine Destabilisierung des Raumes und literarischer Gattungsgrenzen. Das alles werde verbunden mit der Frage, ob und wie die moderne Welt sprachlich überhaupt noch zu erfassen sei (vgl. ebda., S. 453). 
tiziert, die er offensichtlich zu den seinen macht, sich im Stile des brasilianischen Anthropophagismus «einverleibt», zum anderen geht er weit darüber hinaus. Denn aus der Hybridisierung der Lexik entwickelt er im selben Vorwort eine universale Vision von Sprache, die sich mit dem Universalitätsanspruch seiner Poesie rückkoppeln lässt:

Me parece muy bien que las lenguas se invadan las unas a las otras, lo más posible; que las palabras pasen como aeroplanos por encima de las fronteras y las aduanas y aterricen en todos los campos. Acaso a fuerza de invadirse las lenguas lleguemos a tener algún día un solo idioma internacional y desaparezca la única desventaja que presenta la poesía entre las otras artes. ${ }^{85}$

Die unkontrollierte Grenzüberschreitung («por encima de las fronteras y las aduanas») wird hier geradezu paradigmatisch gesetzt: ${ }^{86}$ kein Containerkonzept von Sprache, keine Idee der Reinhaltung, des Purismus, des Borges'schen Lokalen, sondern Offenheit für gegenseitige Befruchtung und Hybridisierung. Sie kommt hier zwar martialisch-technisch als Invasion daher, ${ }^{87}$ ist aber eine, die nicht auf Sieger und Besiegte aus ist, sondern Gegenseitigkeit impliziert und damit eher auf ein Modell der Transkulturation verweist. Als Ideal wird eine gemeinsame, internationale Sprache imaginiert - vergleichbar der als Universalsprache gedachten Kunstsprache Zaum des russischen Futuristen Chlebnikow oder der 1887 von Zamenhof erfundenen Sprache Esperanto -, die Übersetzungen überflüssig und die Poesie zu einer universalen Kunst mache. Hier wird erneut der kosmopolitische Anspruch im Allgemeinen, der die Avantgarde der 1920er Jahre auszeichnet, und Huidobros Ansinnen im Besonderen sichtbar. ${ }^{88}$

85 Vicente Huidobro, Mio Cid Campeador, S. 20f., meine Hervorhebung; Vgl. Marcos Eymar Benedicto: La poética de la autotraducción en tres escritores bilingües franco-hispánicos: Vicente Huidobro, Juan Larrea y Ventura García Calderón, S. 128.

86 Dies ließe sich leicht autobiographisch rückbinden: Grenzen für einen interkontinental Vielreisenden wie Huidobro in den 1910er und 1920er Jahren mit einer Reisedauer von ca. drei Wochen für einen Weg müssen anders im Bewusstsein verankert sein als in einem Schengenraum heutzutage.

87 Der Vergleich mit den Flugzeugen und dem Fliegen verweist auf den technischen Fortschritt, der schon die Futuristen inspiriert hatte und auch in den 1920ern, etwa nach dem ersten NonstopFlug von New York nach Paris durch Charles Lindbergh im Mai 1927 und ohne die Massenbewegungen mit Billigfluglinien heute, faszinierte (vgl. Ana Pizarro: Huidobro: noticias del futuro, S. 448). Ein «Canto to Lindbergh», von Huidobro 1927 auf Englisch verfasst, bleibt auf Spanisch unpubliziert (vgl. Cedomil Goic: Cronología, S. 1396).

Die Luftreise wird als Leitmotiv erkennbar, das auch das seit 1919 entstandene Langgedicht Altazor. Viaje en paracaídas, publiziert 1931, prägt (s.u.).

$88 \mathrm{Paz}$ sieht für die lateinamerikanische Literatur als prägende Bewegungen die Hinwendung entweder zum Kosmopolitismus oder zum Amerikanismus. Für die lateinamerikanische Literatur 
Der Verweis auf die Grenzüberschreitung der «Wörter» - «por encima de las fronteras» - ist jedoch nicht ganz uneigennützig, denn er zielt auch ab auf die «stilistische Verbesserung» der eigenen Muttersprache, wie es im selben Vorwort dann heißt. Denn, so Huidobro, das Spanische sei «schwerfällig», «fest» und «mollig»; «Leichtigkeit» und «Schnelligkeit» würden dieser Sprache gut tun: «Por otra parte, no puede negarse que el castellano es una lengua bastante pesada, tiesa, ajamonada, y que un poco de soltura y rapidez no le haría mal.» ${ }^{89}$

Andere Sprachen (ohne explizit das Französische zu nennen) sind offensichtlich attraktiver für ihn als Dichter, haben ein höheres Prestige und ermöglichen einen Zeitsprung aus dem 19. ins 20. Jahrhundert. ${ }^{90}$

1931, zwei Jahre nach Mio Cid Campeador, erscheint Huidobros radikalstes und erratischstes, die Grenzen des Sprachmaterials zwischen Verständlichkeit und Klang auslotendes Werk Altazor. ${ }^{91}$ Im Vorwort wird die Fremdheit von Sprache als konstitutiv für das poetische Schaffen herausgehoben: «Se debe escribir en una lengua que no sea materna». ${ }^{92}$ Das Vorwort wurde bereits 1918, während des ersten Paris-Aufenthalts, auf Französisch verfasst, seine Existenz

des 20. Jahrhunderts steht außer Frage, dass wesentliche Impulse durch den Kontakt mit Europa, die Auseinandersetzung mit Fremdverstehen und die Konfrontation mit Selbst- und Fremdbild, entstanden sind, so etwa Alejo Carpentiers Konzept des real maravilloso, das in Auseinandersetzung mit und in Abgrenzung von dem merveilleux der Surrealisten entstanden ist, wie er in seinem Vorwort zu El reino de este mundo von 1949 deutlich macht. Borges' criollismo in den 1920er Jahren, der das Lokale bis in die Sprache hinein betont, steht im Gegensatz zu Huidobros auf das Kosmopolitische abzielenden Ideen (vgl. Carlos Démaso Martinez/Andrea Ostrov: Bilingüismo y vanguardia en Vicente Huidobro, S. 214; Jorge Schwartz: Chile; Borges' Vorwort zum Indice de la nueva poesía americana von 1926, herausgegeben zusammen mit Alberto Hidalgo und Vicente Huidobro).

89 Vorwort zu Mio Cid Campeador. In: Vicente Huidobro: Mio Cid Campeador, S. 20f. Vgl. Marcos Eymar Benedicto: La poética de la autotraducción en tres escritores bilingües franco-hispánicos: Vicente Huidobro, Juan Larrea y Ventura García Calderón, S. 128 und Marcos Eymar Benedicto: $L a$ langue plurielle, S. 236-249, der auf weitere Dispute um den Status des Spanischen verweist, u.a. zwischen Unamuno und Gourmont sowie bei García Calderón.

90 Vgl. Marcos Eymar Benedicto: La poética de la autotraducción en tres escritores bilingües franco-hispánicos: Vicente Huidobro, Juan Larrea y Ventura García Calderón, S. 128. Damit ist Huidobro nicht allein unter den hispanoamerikanischen Dichtern, wie Eymar 2011 für die Zeit von 1890 bis 1950 belegt.

91 Yúdice (1978) ordnet Altazor der zweiten Schaffensphase Huidobros zu, in der er sich der Freiheit des Signifikanten und der Kreation widmet (vgl. Karin Hopfe: Vicente Huidobro, der Creacionismo und das Problem der Mimesis, S. 3f.). Die Spiele mit und das Ausprobieren von Sprachmaterial hat Huidobro weder vor noch nach Altazor derart radikal durchgeführt.

92 Vicente Huidobro: Obra poética, S. 732. 
1919 von Cansinos Assens zum ersten Mal erwähnt. ${ }^{93}$ Es zeigt, dass Huidobro sich mit dem Status von Sprache seit den 1910er Jahren beschäftigt und dass seine dichterische Kreation in der Fremdsprache Französisch von Anfang an eine doppelte Dimension hat. ${ }^{94}$ Der Fremdheit der Sprache wird eine poetologische Dimension abgerungen, die sich als Wenden gegen konventionelle Sprache, Sinnzuschreibungen und Ausdrucksformen, als Plädoyer für die Suche nach Neuem deuten lässt. Demnach wäre das Adjektiv «materna» hier im metaphorischen Sinne von «vertraut» zu verstehen, aber es besitzt natürlich auch eine konkrete pragmatische Dimension, da Huidobro während der Pariser Zeit auf Französisch, also nicht in seiner Muttersprache, Gedichte verfasst.

Ähnliche Skepsis gegenüber der (allzu) vertrauten Sprache hat Huidobro auch schon in seinem Vortrag «La poesía» von 1921 in Madrid formuliert. ${ }^{95}$ Ziel des Dichters sei es, nicht auf die normale und kommunikative Funktion von Sprache, sondern auf etwas jenseits davon als ureigentlich Poetisches abzuzielen, eine poetische, weltunabhängige Schöpfung durch das Wort: die «significación mágica» jenseits einer «norma convencional». ${ }^{96}$

Mit dem expliziten Verweis auf das Nicht-Vertraute, Nicht-Tradierte und Nicht-Geerbte im Vorwort zu Altazor wird zwar auch auf das Nicht-Konventionelle verwiesen, aber der Akzent stärker auf die verwendete Sprache und damit das Verhältnis zwischen Signifikat und Signifikant gesetzt. Die (Un-)Vertrautheit einer Sprache hat damit zu tun, dem Signifikanten ein entsprechendes Signifikat (nicht)

93 Das Vorwort wird von Cansinos Assens zum ersten Mal erwähnt in La Correspondencia de España (Madrid, 24.11.1919) und seither (bis 1931, dem Erscheinen des Gesamtwerkes) als Titel für das ganze Werk genommen. Zur komplexen Entstehungs- und Publikationsgeschichte von Altazor vgl. Goic in seiner Einführung in Vicente Huidobro: Obra poética, S. 717-722.

94 Carlos Démaso Martinez/Andrea Ostrov: Bilingüismo y vanguardia en Vicente Huidobro, S. 218, sehen, Zonana $(1994,63)$ zitierend, eine «voluntad de destierro [...] de las formas convencionales de ver y expresar» und Französischschreiben als Form der Legitimation. Die Zweisprachigkeit des Werkes lässt sich, so ihre These, als Kombination bzw. Ergänzung zweier Aspekte verstehen, nämlich eines strategischen Aspekts, in Frankreich mehr Publikum durch ein Werk auf Französisch anzusprechen, und eines poetologischen, der Suche nach einem «universalismo poético más allá de las lenguas» (Ebda., S. 211-214).

Marcos Eymar Benedicto: La langue plurielle, S. 252-254 verweist auf Huidobros frühes Gedicht Adán, in dem Wortschöpfung als Weltschöpfung, thaumaturgisch verstanden wird und deutet die radikal auf Schöpfung ausgerichtete Poetik als Abstreifen von kolonialen Abhängigkeiten Hispanoamerikas.

95 Es wurde als Fragment publiziert im Vorwort zu Temblor de cielo 1931 (vgl. Cedomil Goic: Vorwort. In: Vicente Huidobro: Obra poética, S. 1291).

96 Vicente Huidobro: Obra poética, S. 1296, vgl. auch George Yúdice: Vicente Huidobro y la motivación del lenguaje. Buenos Aires: Ed. Galerna 1978, Marcos Eymar Benedicto: La langue plurielle, S. 252. 
zuweisen zu können. Mehrsprachige Dichtung spielt mit diesem Verhältnis, sie kann Sprache als unsicheres Terrain mit verschwimmenden Grenzen präsentieren, die vertraute Basis, die «norma convencional», aushöhlen. Sie zeigt der Leserschaft ihre (fremd-)sprachlichen Grenzen auf, ermuntert sie zu Semantisierungsversuchen, und, wenn diese vollkommen scheitern (müssen), da es sich z. B. um Phantasiesprachen handelt, ${ }^{97}$ wird der Fokus auf den Signifikanten in seiner Poetizität, Klanglichkeit, seiner Nicht-Referentialisierbarkeit gerichtet. Wie sich nun eine «lengua que no sea materna», eine unvertraute Sprache, in Altazor artikuliert bzw. wie Grenzen zwischen Vertrautem und Nicht-Vertrautem ausgelotet und überschritten werden, sei abschließend kurz an einigen Ausschnitten untersucht.

\section{III.b Altazor (1931): Vexierbilder von fremder und vertrauter Sprache}

Altazor besteht aus einem Vorwort «Altazor o viaje en paracaídas» und sieben nur nummerierten Gesängen sehr ungleicher Länge mit insgesamt 2271 Versen. Das, was mit dem Medium 〈Fallschirm〉 eigentlich eine vertikal ausgerichtete Bewegung von oben nach unten von überschaubarer Dauer wäre, wird - entgegen dem sprachlich und inhaltlich Vertrauten, also den Konventionen dessen, was mit einem Fallschirm machbar ist - ausgedehnt zu einer Reise: Es geht um einen Fall in der Luft, um Sündenfall und immer wieder um die Suche des Dichters, der sich vor allem als Luftreisender - «astro-», «eter-» und «isonauta» - bezeichnet, nach neuer, unverbrauchter Sprache. ${ }^{98}$ Bereits der Neologismus des Titels geht mit der Bildung aus «altura» (Höhe) oder «alto» (hoch) und «azor» (Habicht) über referentielle Belegbarkeit hinaus.

Das Langgedicht ist ludisch, experimentell, es arbeitet mit Klang, Konsonanzen, Assonanzen, Serialisierung von neuen Wörtern, die durch Silbenkombinationen und Umstellungen generiert werden. Es hat etwas dadaistisch Nonsenshaftes, aber auch Rituelles und Litaneihaftes und damit Vertrautes, stößt den Leser

97 Phantasiesprachen werden hier nach Helmich (Werner Helmich: Ästhetik der Mehrsprachigkeit, S. 445) verstanden als «mit literarischen Intentionen als Ganzes frei erfundene künstliche Sprachen».

98 Pizarro (vgl. Ana Pizarro: Huidobro: noticias del futuro, S. 448) spricht von Vermessung des Luftraums, Beschleunigung, neuen Fortbewegungsmedien wie Flugzeug, aber auch dem Fallschirm, und bemerkt: «en Huidobro la incorporación de las percepciones contemporáneas en las formalizaciones discursivas se multiplican» (Ebda., S. 452). 
aber immer wieder auf die Frage nach dem Bezeichneten. ${ }^{99}$ So heißt es in Canto IV, in dem ein lyrisches Ich in Anbetracht der verstreichenden (Lebens-) Zeit nach neuen literarischen Sujets sucht und sich assoziativ treiben lässt, skandiert vom Refrain: «No hay tiempo que perder / [...] Ahora que me siento y me pongo a escribir / ¿Qué hace la golondrina que vi esta mañana» ${ }^{100}$ :

\author{
No hay tiempo que perder \\ Ya viene la golondrina monotémpora / [...] \\ Viene gondoleando la golondrina \\ Al horitaña de la montazonte \\ La violondrina y el goloncelo \\ Descolgada esta mañana de la lunala \\ Se acerca a todo galope \\ Ya viene viene la golondrina \\ Ya viene viene la golonfina $[. . .]^{101}$
}

Das ludische Verfahren erzeugt aus dem Morphem golon- mit Suffixen einen Neologismus mit konsonantischem Reim in insgesamt 14 Variationen. Assonanzen und durch Silbenumstellungen generierte Kofferwörter (palabras portmanteau, oder mots-valise) können von Leser und Leserin teilsemantisiert und dem Spanischen zugeordnet werden, auch wenn es keine Signifikate dazu gibt. Einzelne Zeilen (etwa «Ya viene la golondrina [...] / Se acerca a todo galope» sind zwar in grammatisch korrektem Spanisch gehalten, destabilisieren den Bezug zwischen Signifikant und Signifikat aber durch das semantisch nicht kongruente, kreationistische Bild der herangaloppierenden Schwalbe. Das semantische Syntagma wird durch ein klangliches Paradigma, die Alliteration golondrina - galope überformt, seine Poetizität (nach Jakobson) damit akzentuiert. Doch kreieren die Wortschöpfungen auch neue Signifikanten, die auf etwas surreale Signifikate, etwa eine Hybridisierung aus Violoncello und Schwalbe (im Spanischen wie das Violoncello viersilbig und damit auch von einem klanglichen, poetischen, nicht einem semantischen Prinzip bestimmt) verweisen.

Ähnlich kreativ wie mit der «golondrina» wird im gleichen Gesang mit dem Signifikanten «rodoñol» - im Spanischen nicht existent - umgegangen: auch hier

99 Der berühmteste, mehrfach diskutierte Neologismus des Gedichts, der dessen ludischen Charakter pointiert herausstellt, ist sicher das Palindrom «eterfinifrete» am Ende des Gesangs IV (vgl. Vicente Huidobro: Obra poética, S. 781, S. 824, n. 24 und Karin Hopfe: Vicente Huidobro, der Creacionismo und das Problem der Mimesis, S. 184).

100 Vv. 1110-1114, Vicente Huidobro: Obra poética, S. 772.

101 Vv. 1211-1220, Vicente Huidobro: Obra poética, S. 775f.; vgl. José Ignacio Padilla: Vicente Huidobro: Entrar y salir del lenguaje, S. 235; Esther M. Alarcón-Arana: Exilio e identidad, S. 102f. 
findet sich eine Kombination aus grammatikalisch korrekten Syntagmen und Variationen:

\author{
[...] Pero el cielo prefiere el rodoñol \\ Su niño querido el rorreñol \\ Su flor de alegría el romiñol \\ Su piel de lágrima el rofañol \\ Su garganta nocturna el rosoñol \\ El rolañol \\ El rosiñol ${ }^{102}$
}

Es handelt sich um eine "Jitanjáfora», erfundene Wörter (Sprache), hier offensichtlich ein Vogel, so vermutlich die Teilsemantisierung des Lesers, da vorher von Schwalben («golondrina») die Rede war. Das Terrain von Signifikaten und Referenten ist also äußerst schwammig, eine «ilusión referencial» wird, so Padilla, «aus den Angeln gehoben». ${ }^{103}$ Der Gesang entwickelt Neologismen, die zwar Spanisch klingen, aber nicht im eigentlichen Sinne vertraut und bekannt sind, sondern eine neue, sprachlich generierte Welt entstehen lassen. Erst mit «rosiñol», orthographisch ans Spanische angepasst durch das « » für das französische Phonem «-gn», wird wieder ein zumindest für Französisch kundige Leserinnen und Leser ein bekanntes Signifikat aufgerufen und das ornithologische Register bestätigt. Das französische Fremdwort ist hispanisiert und verfremdet, und, da im Spanischen nicht existent, kann es als Beispiel für das im Vorwort zum Cid evozierte «Eindringen» der einen in die andere Sprache gedeutet werden. ${ }^{104}$

Was das Changieren zwischen verschiedenen (romanischen) Sprachen angeht, ist der letzte, 66 Zeilen umfassende Gesang von Altazor noch extremer. Hier wird die Sinnzuschreibung fast unmöglich, denn er ist fast vollständig in unbekannter «Phantasiesprache» gehalten und lässt sich daher sehen als Metapher für die von Huidobro angesteuerte neue Sprache der Dichtung jenseits nationaler Zuschreibungsmöglichkeiten und Verortungen.

Der Gesang beginnt und endet mit Vokalgruppen aus a, i und o bzw. $u$, die das Ende von Gesang 4 wieder aufnehmen. Sie könnten auf Alpha und Omega verweisen, aber durch die unterschiedlichen Kombinationen, die je anders ge-

102 Vv. 1246-1252, Vicente Huidobro: Obra poética, S. 776.

103 Vgl. José Ignacio Padilla: Vicente Huidobro: Entrar y salir del lenguaje, S. 222.

104 An anderer Stelle im Gedicht wird die spanische Version «ruiseñor» (C. V, v. 1496, Vicente Huidobro: Obra poética, S. 785) verwendet. Der Vogel kann als Chiffre für die Dichtung und persönliches Leitmotiv von Huidobro gesehen werden, der wohl - vergeblich - versucht hat, Nachtigallen in Chile heimisch zu machen. 
sprochen neue Signifikate ergeben, ist eine klare Festlegung im Gegensatz zu Huidobros frühem Gedicht Adân ${ }^{105}$ nicht möglich:

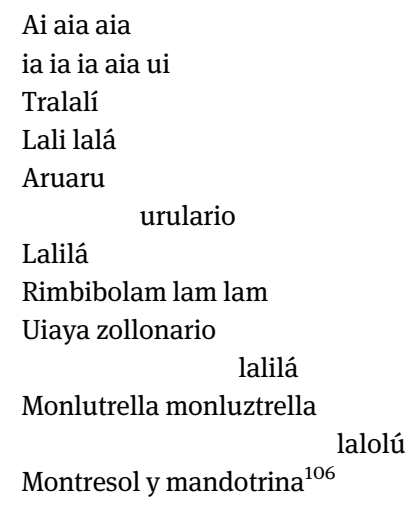

Die Deutung hängt von der jeweiligen Ausführung ab, wie in einer Partitur und wie auch in Hugo Balls Dada-Gedicht von 1917: Die Silbenkombination a i kann sich als Interjektion «ai» lesen lassen, die im Spanischen und Französischen Schmerz anzeigt, als Spanisch räumliches Deiktikum «Ahí», oder onomatopoetisch für den Vogelgesang, schließlich als sinnfreie Silben mit Echo oder als Erfindungen. ${ }^{107}$ Es gibt eine unauflösbare Spannung zwischen Allegorie und Ironie, so Padilla, Schrei, Gesang und trällernden Silben («tralalí»), schmerzhaftem Stöhnen und dem Benennen des universalen Grundmaterials, der zentralen Vokale für jede Dichtung. Es ist eine Befreiung der Poesie, weg von der Sinnzuschreibung hin zu den Grundelementen jeder Sprache. Die zitierten Zeilen haben zwar Anklänge an indigene oder baskische Silben («aruaru») oder entsprechen hispanischen Wortbildungsregeln («zollonario»), sind aber fast nicht mehr semantisierbar. Einzig Anklänge an das Französische sind erkennbar in den Versen, die die Silbe «mon» (als adjektivisches Possessivpronomen, oder auch als konjugiertes Verb «montre») verwenden: «monlut(rella) monluz(trella), montresol». Eine Teilsemantisierung als Französisch ist möglich, allerdings ohne dass die Sinnstiftung nachhaltig und stabil funktioniert, denn sie wird durch Spanisch klingende Wortbestandteile («-luz» und «-sol») konterkariert und destabilisiert. Die französisch-spanische Mehrsprachigkeit, die gerade von hispanoamerikanischen Dichtern auf der Suche nach Autonomie und Legitimierung ab Ende des

105 Vgl. Marcos Eymar Benedicto: La langue plurielle, S. 251f.

106 Vv. 2205-2217; 2269-2271, Vicente Huidobro: Obra poética, S. 807f.

107 Vgl. José Ignacio Padilla: Vicente Huidobro: Entrar y salir del lenguaje, S. 238. 
19. Jahrhunderts praktiziert wird, und zwar in der Form, dass Französisch in ein überwiegend spanischsprachiges Werk eingebettet wird, ${ }^{108}$ wird hier weit hinter sich gelassen. Die Sprachen scheinen moment- oder silbenweise auf und verklingen wieder.

Umso mehr fallen in dieser semantischen Instabilität der 66 Verse die wenigen Neologismen auf, die aufgrund ihrer griechischen Silben vergleichsweise einfach semantisierbar sind, nämlich «isonauta» und «eternauta». ${ }^{109}$ Sie nehmen das Motiv der Reise, der Bewegung durch den Raum (in der Luft, zu Wasser, worauf der «mareciente» in v. 2235 anspielen könnte) wieder auf, verweisen auf den «aeronauta», das durch die Luft reisende lyrische Ich aus Canto VI, ${ }^{110}$ evozieren die zeitliche Dimension der Unendlichkeit und die räumliche der beständigen Mobilität.

Das Langgedicht endet mit den drei Vokalen a, i und o, einzeln oder als Gruppe gefasst, versehen mit einem graphischen, eine andere Dimension, nämlich Kommentare, evozierenden Zeichen, der runden Klammer:

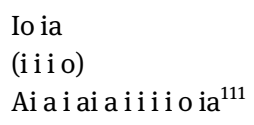

Die das Gedicht beschließende Vokalkombination «ia» ist zuerst einmal die Umkehrung vom Beginn des Gesangs und des Anfangs der letzten Zeile. Sie kann als Spanisch «ya» - «vorbei», «zu Ende» - gedeutet werden, selbstreferentiell auf das eigene Werk, auf das tchechische «ya» des Gedichttitels aus Automne régulier verweisen oder spielerisch auf den Ruf des Esels als Echo. «Io» als italienisch «Ich», oder spanisch-kastilisch «Yo» von der drittletzten Zeile, je nach Ausführung auch in der vor- und der letzten Zeile anklingend, könnte noch einmal das lyrische Ich bzw. dessen Versatzstücke evozieren.

Es ist keine Mutter-Sprache mehr, keine konventionelle vertraute Sprache, die sich hier am Ende von Altazor bietet, sondern eine neue Sprache, die erprobt wird, an Grenzen und über sie hinausgeht und sich als Material für jeden Dichter, sprachunabhängig, anbietet, als utopischer Weg zur Universalsprache der Poesie.

$108 \mathrm{Vgl}$. Marcos Eymar Benedicto: La langue plurielle. Le bilinguisme franco-espagnol dans la littérature hispano-américaine (1890-1950). Paris: Harmattan 2011.

109 Vv. 2231, 2235, ebda., S. 807f.

110 Vgl. ebda., S. 806.

111 Vv. 2269-2271, Ebda., S. 808. 


\section{Conclusio: Von der Freiheit des Künstlers als Migrant}

Der Beitrag ist der Frage nachgegangen, wie die Pariser Migrationserfahrung und kulturelle Innovation im Werk Vicente Huidobros (1893-1948), einem der herausragenden chilenischen Dichter des 20. Jahrhunderts, ineinanderwirken. Zuerst wurde die biographische Ebene in den Blick genommen und untersucht, wie der Migrant Huidobro sich verortet oder eben seine Mobilität herausstellt. Da eine unmittelbare biographische Deutung seines dichterischen Werks methodisch problematisch ist, wurde hierzu auf faktuale Texte, nämlich Interviews, Manifeste und Briefe zurückgegriffen, die sich auf die Zeit der Parisaufenthalte beziehen. In ihnen entwirft Huidobro performative Zugehörigkeiten. Auffällig ist der exzentrische, kritische und schonungslose Blick auf das hinter sich gelassene Heimatland Chile, den der Künstler gerade durch seine Mobilität legitimiert, und das emphatische Bekenntnis zu Paris, das allerdings nicht als nationaler Raum, sondern als transnationales Zentrum von befruchtendem künstlerischen Austausch und Innovation geschätzt wird. Die einzige Zugehörigkeit, die Huidobro zugesteht und $\mathrm{zu}$ der er sich bekennt, ist die $\mathrm{zu}$ der grenzüberschreitenden, universalen Gemeinschaft der «wahren» Dichter, die er im Gegensatz sieht zu den Möchtegerndichtern oder «presque-poètes», wie er sie in seinem Manifest zum créationnisme von 1925 abfällig nennt. ${ }^{112}$ Die «Verstrickung» und «Verwurzelung in der Heimat» (Flusser) legt er jedoch nicht gänzlich ab - dazu sind seine Beziehungen, seine Reisen, sein Engagement dort zu intensiv.

Auf künstlerischer Ebene ist die Verbindung von Migration und kultureller Innovation hingegen eindeutig. Huidobro lotet den Freiraum, den ihm die neue Sprache Französisch bietet, konsequent aus, ohne sich letztendlich nur für sie zu entscheiden, sondern den Zwischenraum der Übersetzung zwischen der Muttersprache und der neuen in beiden Richtungen zur Destillation, zum WiederSchreiben seiner Gedichte zu nutzen.

Poetologisch zeigt sich die Freiheit des Migranten in der Suche nach einer unverbrauchten poetischen Sprache, einer «Ur-Sprache» unabhängig von jeweiligen Mutter-/Nationalsprachen - «una lengua que no sea materna», heißt es im Vorwort zu Altazor, bereits 1919 formuliert -, mit der er sich gegen das zu Vertraute, Abgegriffene wendet und neue Dimensionen eröffnen will. Diese poetologische Dimension findet sich am stärksten ausgeprägt in seinen Anmerkungen zur Übersetzbarkeit von Lyrik, den Ideen zur willkommenen Hybridisierung von

112 Vicente Huidobro: Obra poética, S. 1337. 
Sprachen und dem Einsatz von Fremdsprachen in seinem (lyrischen) Werk, die nur in Altazor von 1931 über die Grenzen des Verständlichen hinausgehen. Hier, vor allem in der Phantasiesprache des letzten Gesangs wird sein Ziel einer Poesie als universale, nicht durch Sprachgrenzen gehemmte und limitierte Kunstform, in einer hybriden, Nationengrenzen überschreitenden Sprache bzw. als Fernziel in einer universalen Kunstsprache erkenn- und hörbar. ${ }^{113}$

Heimat heißt auch Mutter-«Sprache». Gegen diese, die geerbt, übernommen, einfach «da» ist, wendet sich Huidobro bewusst und entscheidet sich in Freiheit für die fremde, neue Sprache, um von da aus seine Idee einer kosmopolitischen Poesie zu verfolgen.

\section{Literaturverzeichnis}

Alarcón-Arana, Esther M.: Exilio e identidad: superación de las poéticas clásica y cristiana en Altazor de Vicente Huidobro. In: Scritture Migranti 8 (2014), S. 85-105.

Alcantud, Victoriano: Creacionismo y cubismo literario: Vicente Huidobro, «el que trajó las gallinas». In: Victoriano Alcantud (Hg.): Hacedores de imágenes. Propuestas estéticas de las primeras vanguardias en España (1918-1925). Granada: Ed. Comares 2014, S. 106-136.

Ángel, Roberto: Juan Emar y la crítica. In: Hispamérica XLVII, 139 (2018), S. 97-103.

Balderston, Daniel: Huidobro and the Notion of Translatability. In: Fragmentos: Revista de Lingua e Literatura Estrangeiras da Universidade Federal de Santa Catarina 3, 1 (1990), S. 59-74.

Bosi, Alfredo: La parábola de la (sic) vanguardias latinoamericanas. In: Jorge Schwartz (Hg.): Las vanguardias latinoamericanas. Textos programáticos y críticos. Madrid: Cátedra 1991, S. 13-63.

Castro Morales, Belén: Ver y palpar: en el hipertexto de la escritura creacionista. In: Vicente Huidobro: Obra poética. Ed. crítica de Cedomil Goic (coord.). Madrid u. a.: Colección Archivos 2003, S. 1507-1525.

Crepón, Marc: Ce qu'on demande aux langues (autour du Monolinguisme de l'autre). In: Raisons politiques 2 (2001), S. 27-40.

Cruchaga, Ángel: El creacionismo y sus apóstoles en Europa (1919). In: Cecilia García-Huidobro (Hg.): Vicente Huidobro a la intemperie. Entrevistas (1915-1946). Santiago de Chile: Ed. Sudamericana 2000, S. 32-40.

De Costa, René (Hg.): Vicente Huidobro y el creacionismo. El escritor y la crítica. Madrid: Taurus 1975.

De Costa, René (Hg.): Careers of the Poet. Oxford: UP 1984.

113 Die chilenische Schaffensphase nach 1932, die bisher weniger stark in den Blick genommen wurde, ist von der Rückkehr zu vertrauteren Ausdrucksformen geprägt, der Glaube in die Erneuerungskraft der Kunst mit den Erfahrungen des Zweiten Weltkriegs, den er z.T. als Kriegsberichterstatter miterlebte, massiv gesunken (vgl. Óscar Hahn: Vicente Huidobro: muerte y transfiguración. In: Vicente Huidobro: Últimos poemas (1948). Santiago: LOM 2011, S. 9 im Vorwort zu den postum erschienenen Últimos poemas (1948) von Huidobro). 
De la Fuente, José Alberto: Vicente Huidobro: el adelantado que no escuchamos. Santiago de Chile: Universidad Católica Silva Henríquez 2010.

Deleuze, Gilles/Guattari, Felix: Traité de nomadologie. La machine de guerre. In: Gilles Deleuze/ Felix Guattari (Hg.): Mille Plateaux II. Paris: Minuit 1980, S. 434-527.

Démaso Martinez, Carlos/Ostrov, Andrea: Bilingüismo y vanguardia en Vicente Huidobro. In: Axel Gasquet (Hg.): Écrivains multilingues et écritures métisses: l'hospitalité des langues. Clermont-Ferrand: Presses Universitaires Blaise Pascal 2007, S. 211-218.

Derrida, Jacques: Le Monolinguisme de l'autre. Ou la prothèse d'origine. Paris: Ed. Galilée 1996. Dolle, Verena: Amerika als Ort der Freiheit? Die Eroberung Mexikos als Erinnerungsort in «Captain from Castile» (USA, 1947). In: Ute Fendler/Monika Wehrheim (Hg.): Entdeckung, Eroberung, Inszenierung. Filmische Versionen der Kolonialgeschichte Lateinamerikas und Afrikas. München: Meidenbauer 2007, S. 27-52.

Duarte de Oliveira, Maria Rosa: A representação do africano na literature brasileira: a poesia Pau-Brasil de Oswald de Andrade. In: Verena Dolle/Helena Bonito Pereira u.a. (Hg.): Migrações literárias e artísticas: África - Brasil - Europa. Berlin: Peter Lang 2018, S. 121130.

Emar, Jean: Con Vicente Huidobro. In: Cecilia García-Huidobro: Vicente Huidobro a la intemperie. Entrevistas (1915-1946). Santiago de Chile: Ed. Sudamericana 2000, S. 56-62.

Eymar Benedicto, Marcos: La poética de la autotraducción en tres escritores bilingües francohispánicos: Vicente Huidobro, Juan Larrea y Ventura García Calderón. In: Pierre Civil/ Françoise Crémoux (Hg.): Actas del XVI Congreso de la Asociación Internacional de Hispanistas: Nuevos caminos del hispanismo. París, del 9 al 13 de julio de 2007. Madrid/Frankfurt: Iberoamericana/Vervuert 2010. <https://cvc.cervantes.es/literatura/aih/pdf/16/ aih_16_2_015.pdf> [27.11.2019].

Eymar Benedicto, Marcos: La langue plurielle. Le bilinguisme franco-espagnol dans la littérature hispano-américaine (1890-1950). Paris: Harmattan 2011.

Flusser, Vilém: Von der Freiheit des Migranten. Hamburg: CEP Europäische Verlagsanstalt 2013.

García-Huidobro, Cecilia (Hg.): Vicente Huidobro a la intemperie. Entrevistas (1915-1946). Santiago de Chile: Ed. Sudamericana 2000.

Goic, Cedomil: Cronología. In: Vicente Huidobro: Obra poética. Herausgegeben von Cedomil Goic. Madrid u. a.: Colección Archivos 2003, S. 1383-1406.

Goic, Cedomil: Introducción (el espejo de agua). In: Vicente Huidobro: Obra poética. Herausgegeben von Cedomil Goic. Madrid u. a.: Colección Archivos 2003, S. 379-389.

Goic, Cedomil: Introducción (Manifiestos). In: Vicente Huidobro: Obra poética. Herausgegeben von Cedomil Goic (coord.). Madrid u. a.: Colección Archivos 2003, S. 1291-1293.

Hahn, Óscar: Vicente Huidobro: muerte y transfiguración. In: Vicente Huidobro: Últimos poemas (1948). Santiago: LOM 2011.

Han, Petrus: Soziologie der Migration. Erklärungsmodelle, Fakten, Politische Konsequenzen, Perspektive. Stuttgart: Lucius \& Lucius Verlagsgesellschaft ${ }^{2} 2005$.

Helmich, Werner: Ästhetik der Mehrsprachigkeit. Zum Sprachwechsel in der neueren romanischen und deutschen Literatur. Heidelberg: Universitätsverlag Winter 2016.

Hopfe, Karin: Vicente Huidobro, der Creacionismo und das Problem der Mimesis. Tübingen: Narr 1996.

Huidobro, Vicente: Espagne. In: L'Esprit Nouveau. Revue Internationale Illustrée de L'Activité Contemporaine. Arts, Lettres, Sciences 18 (1923), S. 31-36. http://arti.sba.uniroma3.it/ esprit/viewer/web/viewer.html?\&file=Li4vLi4vcGRmLOVzcHJpdE5vdXZIYXUtRIRfMTgucGRm [27.11.2019]. 
Huidobro, Vicente: Mio Cid Campeador, pres. de Ángeles Pérez López. México: Universidad Autónoma Metropolitana 1997.

Huidobro, Vicente: Obra poética. Herausgegeben von Cedomil Goic. Madrid u. a.: Colección Archivos 2003.

Infante, Ignacio: The translatabilitiy of planetary poiesis: Vicente Huidobro's Creacionismo in Temblar de cielo/Tremblement de ciel. In: Ders.: After Translation: The Transfer and Circulation of Modern Poetics across the Atlantic. New York: Fordham University Press 2013, S. 5180.

Lihn, Enríque: El lugar de Huidobro (1970). In: René da Costa (Hg.): Vicente Huidobro y el creacionismo. Madrid: Taurus 1975, S. 363-384.

Lipphardt, Anna: Der Nomade als Theoriefigur, empirische Anrufung und Lifestyle-Emblem. Auf Spurensuche im Globalen Norden. In: Aus Politik und Zeitgeschichte 26/27 (2015). URL: http://www.bpb.de/apuz/208257/der-nomade-als-theoriefigur-empirische-anrufung-undlifestyle-emblem-auf-spurensuche-im-globalen-norden, S. 1-6.

Morales, André: Huidobro en España. In: Vicente Huidobro: Obra poética. Herausgegeben von Cedomil Goic. Madrid u. a.: Colección Archivos 2003, S. 1409-1422.

Oliver, José F.A.: Gastling. Berlin: Das Arabische Buch 1993.

Osorio Tejeda, Nelson: Prólogo. In: Ders. (Hg.): Manifiestos, proclamas y polémcias de la vanguardia literaria hispanoamericana. Caracas: Biblioteca Ayacucho 1988, S. ix-xl.

Padilla, José Ignacio: Vicente Huidobro: Entrar y salir del lenguaje. In: Ders.: El terreno en disputa es el lenguaje: ensayos sobre la poesía latinoamericana. Madrid/Frankfurt a. M.: Iberoamericana/Vervuert 2014, S. 207-238.

Paz, Octavio: Los hijos del limo. Del romanticismo a la vanguardia. Barcelona: Seix Barral ${ }^{3} 1990$ (Biblioteca de Bolsillo).

Pellicer, Rosa: La tradición en la vanguardia. Mío Cid Campeador de Vicente Huidobro. In: Anales de Literatura Hispanoamericana 26 (1997), S. 485-495.

Pizarro, Ana: Huidobro: noticias del futuro. In: Patricio Lizama/María Inés Zaldívar: Las vanguardias literarias en Chile. Bibliografía y antología crítica. Madrid/Frankfurt a. M.: Iberoamericana/Vervuert 2009, S. 439-456.

Pries, Ludger: Internationale Migration. Bielefeld: Transcript ${ }^{4} 2013$.

Rojas, Waldo: En torno a Automne régulier y Tout à coup: culminación y proyecciones de la andanza poética francesa de Vicente Huidobro. In: Vicente Huidobro: Obra poética. Herausgegeben von Cedomil Goic. Madrid u. a.: Colección Archivos 2003, S. 1440-1463.

Rojas, Waldo: Huidobro a la hora de las vanguardias: acercamiento a su obra poética en francés. In: Patricio Lizama/María Inés Zaldívar (Hg.): Las vanguardias literarias en Chile. Bibliografía y antología crítica. Madrid/Frankfurt a. M.: Iberoamericana/Vervuert 2009, S. 471-505.

Rojas Jiménez, Alberto: Vincent Huidobro (1925). In: Cecilia García-Huidobro (Hg.): Vicente Huidobro a la intemperie. Entrevistas (1915-1946). Santiago de Chile: Ed. Sudamericana 2000, S. 48-52.

Sánchez-Pardo, Esther: Vicente Huidobro and William Carlos Williams. Hemispheric Connections or How to Create Things with Words. In: International Yearbook of Futurism Studies 7 (2017), S. 182-205.

Santini, Benoît: L'écriture poétique en français dans Amour à mort de César Moro (Pérou) et Horizon carré de Vicente Huidobro (Chili). Création de nouvelles réalités et liberté artistique. In: Françoise Morcillo (Hg.): Littératures en mutation: écrire dans une autre langue. Orléans: Éd. Paradigme 2013, S. 215-228. 
Sarabia, Rosa: Eclipse de imagen: los poemas pintados de Vicente Huidobro. In: Vicente Huidobro: Obra poética. Herausgegeben von Cedomil Goic. Madrid u. a.: Colección Archivos 2003, S. 1423-1439.

Schwartz, Jorge: Chile. In: Jorge Schwartz: Las vanguardias latinoamericanas. Textos programáticos y críticos. Madrid: Cátedra 1991, S. 65-99.

Teitelboim, Volodia: Huidobro, la marcha infinita. Santiago de Chile: Ed. Sudamericana 1997.

Vastchenko, Alexis: Vicente Huidobro ou la création nomade. Une poésie à l'échelle du monde. In: Beïda Chikhi (Hg.): Destinées voyageuses. La patrie, la France, le monde. Paris: Presses de l'Université Paris-Sorbonne 2006, S. 147-162.

Yúdice, George: Vicente Huidobro y la motivación del lenguaje. Buenos Aires: Ed. Galerna 1978.

Zonana, Víctor Gustavo: Metáfora y simbolización literaria en la poética y la poesía de los movimientos hispanoamericanos de vanguardia: Altazor de Vicente Huidobro. Mendoza: Ed. de la Facultad de Filosofia y Letras, Universidad Nacional de Cuyo 1994. 